\title{
Application of iron-based magnetic nanoparticles stabilized with triethanolammonium oleate for theranostics
}

\author{
Piotr Pawlik ${ }^{1}$, Barbara Blasiak ${ }^{2, *}$ (1), Joanna Depciuch ${ }^{2}$, Marcin Pruba ${ }^{1}$, Diana Kitala ${ }^{3}$, \\ Svetlana Vorobyova ${ }^{4}$, Malgorzata Stec ${ }^{5}$, Maxim Bushinsky ${ }^{6}$, Artem Konakov ${ }^{4}$, \\ Jaroslaw Baran ${ }^{6}$, Julia Fedotova ${ }^{7}$, Oleg Ivashkevich ${ }^{4}$, Magdalena Parlinska-Wojtan ${ }^{2}$, and \\ Alexey Maximenko ${ }^{8}$ \\ ${ }^{1}$ Faculty of Production Engineering and Materials Technology, Częstochowa University of Technology, Armii Krajowej 19, \\ 42-200 Częstochowa, Poland \\ ${ }^{2}$ Institute of Nuclear Physics, Polish Academy of Sciences, Radzikowskiego 152, 31-342 Krakow, Poland \\ ${ }^{3}$ Dr Stanislaw Sakiel Centre for Burn Treatment, Jana Pawła II 2, 41-100 Siemianowice Ślaskie, Poland \\ ${ }^{4}$ Research Institute for Physical Chemical Problems, Belarusian State University, Leningradskaya str. 14, 220006 Minsk, Belarus \\ ${ }^{5}$ Department of Clinical Immunology, Institute of Pediatrics, Jagiellonian University Medical College, Sw. Anny 12, 30-663 Kraków, \\ Poland \\ ${ }^{6}$ Scientific-Practical Materials Research Centre NAS of Belarus, 220072 Minsk, Belarus \\ ${ }^{7}$ Research Institute for Nuclear Problems of Belarusian State University, Bobruyskaya11, 220030 Minsk, Belarus \\ ${ }^{8}$ SOLARIS National Synchrotron Radiation Centre, 30-392 Kraków, Poland
}

Received: 8 February 2021

Accepted: 8 June 2021

Published online:

29 January 2022

(C) The Author(s) 2022

\section{ABSTRACT}

The novel iron-oxide nanoparticles (NPs) stabilized with triethanolammonium oleate were produced. The specimens were divided into two groups: the top NPs (extracted from the supernatant) and the bottom NPs (nanoparticles sedimented at the bottom of the flask during centrifugation), respectively. The XRD and Mössbauer studies revealed a presence of the $\mathrm{Fe}_{3} \mathrm{O}_{4}$ phase in both types of nanoparticles. Furthermore, the formation of maghemite layer on the surface of nanoparticles was observed. Average particle sizes determined from TEM and XRD studies were lower than the superparamagnetic limit for the magnetite NPs. For glycerol dispersions of both types of NPs, when exposed to $100 \mathrm{kHz}$ external magnetic field, a significant heat release was observed. Furthermore, the contrasts of $T_{1}$ - and $T_{2}$-weighted MR images were significantly dependent on the concentration of NPs in their water solutions. Additionally, the reductions of the relaxation times were different for the top and the bottom NPs. The viability studies of the colon cancer cells have shown low cytotoxicity of both types of NPs due to their coating with triethanolammonium oleate, which confirm the possibility to apply the NPs for MRI-guided hyperthermia.

Handling Editor: Dale Huber.

Address correspondence to E-mail: Barbara.Blasiak@ifj.edu.pl 
Moreover, the presence of NPs did not cause greatest increase of the number of apoptotic cells in the human dermal fibroblasts' culture and has stimulated proliferation of those cells, revealing great potential of the NPs in regenerative medicine.

\section{GRAPHICAL ABSTRACT}

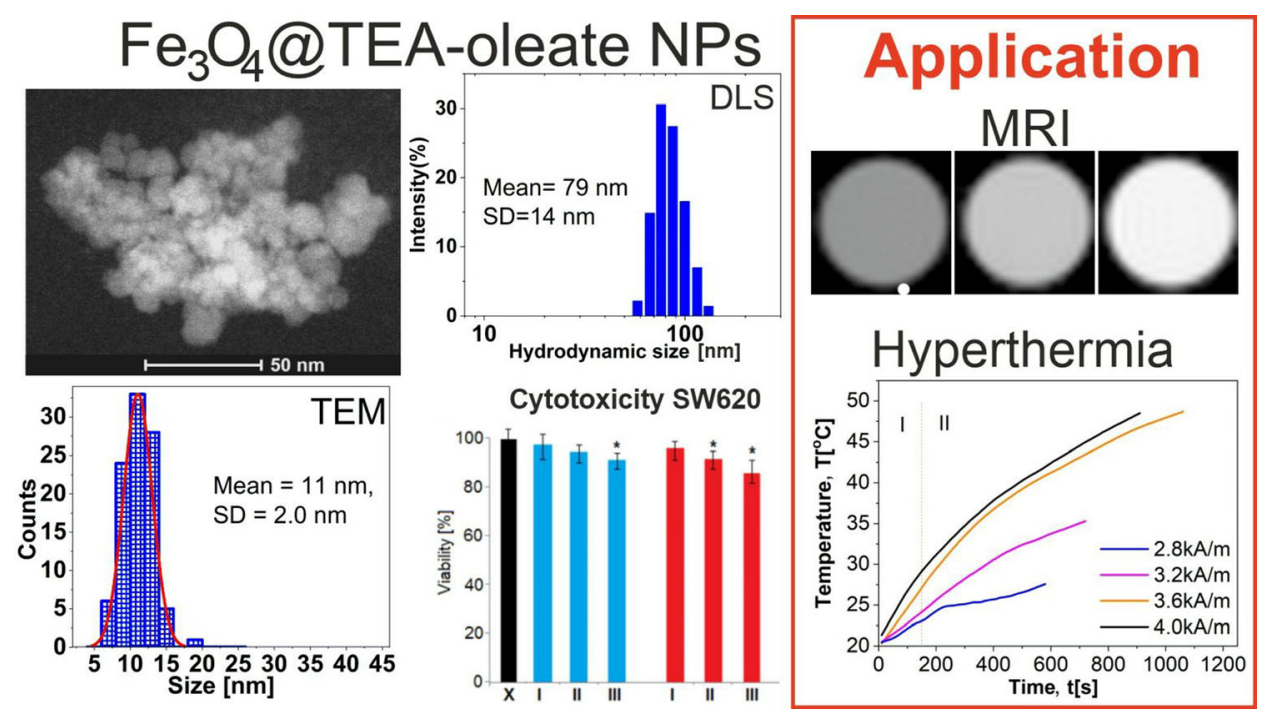

\section{Introduction}

The unique properties of nanomaterials are currently utilized in the nanomedicine aiming to increase the sensitivity and accuracy of diagnostic methods, as well as to create new generations of pharmacological agents used in targeted therapies. They are also utilized to improve chronic wound healing and to penetrate biofilm. In particular, iron-oxide (i.e., magnetite and maghemite) nanoparticles (NPs) exhibiting low cytotoxicity can be produced in large quantities, which make them promising in the nanomedicine for diagnostics and therapy. The superparamagnetic iron oxide nanoparticles (SPIONs) and ultra-small $(5-10 \mathrm{~nm})$ superparamagnetic iron oxide nanoparticles (USPIONs) have been used for labeling of both the mesenchymal and neuronal stem cells isolating them from the cell suspension [1], as well as for their visualization and monitoring with magnetic resonance imaging (MRI)
[2-4], which is important for the stem cell transplantation. These properties are often enhanced by the ability to remotely control their delivery in vivo by external magnetic field, ensuring targeted delivery to the tumor cells. Furthermore, they can be used in the magnetic hyperthermia-an adjuvant therapy in the cancer treatment [5-9]. This technique provides local heating of cancer tissue during the magnetization reversal of magnetic iron-oxide NPs subjected to the alternating external magnetic field. The hyperthermia is based on magnetization dynamics of magnetic NPs, which is determined by the orientation of their magnetic moments along a certain direction. The characteristic time of such orientation depends on the specific mechanisms of the magnetic moment relaxation: either by rotation of the entire particle with a rigidly fixed magnetic moment (Brownian relaxation), or by rotation of the magnetic moment relative to the particle itself (Néel relaxation) $[10,11]$. During the Néelian relaxation, the heating occurs due to the energy loss, when the individual 
magnetic moments rotate within the particles (hysteresis loss). On the other hand, in the Brownian relaxation, the heat is generated by the physical rotation of magnetic particles in external magnetic field. Nevertheless, both types of relaxations can occur at the same time [12]. The magnetic hyperthermia can be particularly useful to treat cancer difficult to reach by direct surgical intervention.

The cancer wound healing is impaired, and it is crucial to understand how potential anticancer therapy based on $\mathrm{Fe}_{3} \mathrm{O}_{4}$ NPs may be used to improve the wound healing. Wound healing is also hindered in the chronic wounds. Chronic wounds preceded $85 \%$ of amputations and five-year mortality rate after developing a diabetic ulcer is approximately 40\%; therefore, proper treatment of wounds is crucial [13]. Chronic wounds are attributed to senescent cell populations with impaired proliferative and secretory possibilities [14]. Unlike the traditional wound dressings, NPs are designed to have a biological activity on its own and thus impact the wound area [15]. What is more, NPs can be used as carriers for growth factors and antimicrobial particles. Moreover, it is known that the combination of Ag nanoparticles with $\mathrm{Fe}_{3} \mathrm{O}_{4}$ can overcome typical for bacterial biofilm problems of the persistence of chronic wounds, as they penetrate and eradicate biofilms when applying a magnetic field [16]. Yang Y. et al. emphasized that PLGA coating of $\mathrm{Ag}-\mathrm{Fe}_{3} \mathrm{O}_{4} \mathrm{NPs}$ could significantly maintain the antibacterial activity and avoid bacterial adhesion to the implant [17]. However in infected wounds, silver is beneficial for the first, few days/ weeks, after which non-silver dressings should be chosen [18]. Still these particles have to remain sterile, have low cytotoxicity and high biocompatibility. Most preferable if the nanoparticles would stimulate viability or proliferation in fibroblast population which may break non-healing circle of chronic wound. Human skin wounds heal mostly by the reparative wound healing, which largely involves the dermal fibroblast [19]. Fibroblasts are critical in all three phases of the wound healing (inflammation, proliferation and remodeling). These cells play a pivotal role in the deposition of extracellular matrix (ECM) components, wound contraction and remodeling of new ECM [20]. Impairment in fibroblasts functionality may result in pathological wound healing [21]. Persistent inflammation observed in chronic wounds is associated with an increase of the ROS levels and leads to tissue damage. Prolonged degradation of extracellular matrix (ECM) is inextricably linked to a poor response of fibroblasts present in wound. Therefore, usage of iron-oxide nanoparticles has also enormous potential to promote selfhealing mechanisms that can mimic regeneration [22].

While various methods have been used for the synthesis of SPIONs and USPIONs, co-precipitation and thermal decomposition are the most frequent. Other methods include sol-gel, pyrolysis and hydrothermal techniques [23, 24]. In the last decade, the microwave-driven synthesis method was frequently utilized and has proven to be very effective [25]. Each of these methods has their advantages and drawbacks. For example, the microwave-driven synthesis technique has two main drawbacks: high equipment cost and difficulty to monitor kinetics of NPs' nucleation and growth processes [26]. The coprecipitation method is simpler, cheaper and is environmentally friendly. However, the fabricated NPs are normally polydisperse in the liquid medium. On the other hand, the thermal decomposition process allows to produce monodisperse and well-crystallized NPs. The drawbacks of the method are long time of reactions and requirement of organic solvents [24].

Magnetic iron-oxide NPs have relatively low cytotoxicity; however, their surface has to be modified in order to prevent their agglomeration and subsequent sedimentation. The agglomeration is caused by attraction of NPs due to their strong magnetic dipole-dipole and Van der Waals interactions [27]. In the case of iron-oxide NPs produced by the thermal decomposition method, chemical adsorption of oleic acid or oleylamine on their surface creates hydrophobic NPs, which allows their dispersion in organic solvents only, making them unsuitable for biomedical applications [28]. Moreover, there are conflicting reports concerning the effect of hydrophobic coatings on cytotoxicity of NPs. A positive influence of hydrophobic oleic acid coating on the cytotoxicity of nanoparticles was reported in [29]. On the other hand, there suggested that the oleic acid coating may induce cytotoxicity and genotoxicity $[30,31]$. To make them water soluble, the surface of the nanoparticles has to be further modified and cytotoxicity of the final NPs depends on the applied coating procedure [32]. For example, NPs can be encapsulated in $\mathrm{aiO}_{2}$ shell [33] or functionalized by cystine [34]. Combining the fabrication of iron- 
oxide NPs by thermal decomposition method with their further encapsulation in the $\mathrm{SiO}_{2}[35,36]$ or cystine $[37,38]$ shell is a very effective technique that allows producing monodisperse NPs with required properties and effectiveness of application, for example for MRI. However, the presence of the small amount of toxic waste (i.e., cyclohexane, hexane, 1-octadecane, acetone, methanol, toluene, etc.) after thermal decomposition and encapsulation is inevitable; therefore, the synthesis is no longer ecofriendly. In mass production, a compromise between their physical properties, costs as well as an impact on the environment should be considered. Also, if NPs are to be used in clinical and commercial application methods of scaling up, the reactions should be considered. In case of the water-based coprecipitation method, allowing fabrication of polydisperse iron-oxide NPs, almost no waste products remain. This type of process can be performed in a continuous way avoiding the use of high-temperature boiling solvents. Furthermore, relatively noncomplicated post-modification steps may be applied in some cases [23, 24]. Moreover, most likely the broad distribution of particle sizes produced by the co-precipitation has a moderate effect on the size dependence of reversal losses, which are very important in effectiveness of hyperthermia [10, 39]. Stabilization of iron-oxide NPs produced by the coprecipitation method is also an issue, as the agglomeration and subsequent sedimentation may occur immediately after precipitation of NPs [40]. Therefore, the fabricated iron-oxide NPs can be subsequently stabilized via the peptization effect, which prevents the agglomeration of NPs by electrostatic repulsion. Using of tetramethylammonium hydroxide, perchloric acid, citric acid, nitric acid, and acrylic acid in the role of peptizing agents was reported [40-42]. Application of inorganic and toxic peptizing agents lead to the particles being incompatible for biomedical applications. Therefore, many different solutions developed in order to deal with this incompatibility have been presented in the last decades [43]. One of them is the use of triethanolamine or one of its salt, for example triethanolammonium oleate, as a coating agent. They are water-soluble reagents, which have a low systemic toxicity via all routes of absorption [44, 45]. For example, it was shown that triethanolamine can prevent agglomeration and sedimentation of the iron-oxide nanoparticles. Xia et al. [46] and Han et al. [47] have used triethanolamine as ligands to the iron precursors in the hydrothermal method, which allowed to fabricate triethanolamine-coated $\mathrm{Fe}_{3} \mathrm{O}_{4}$ nanocrystals with excellent magnetic properties. Maity et al. [48] fabricated water-soluble magnetic nanoparticles by hightemperature decomposition of $\mathrm{Fe}(\mathrm{acac})_{3}$ in a liquid mixture of tri(ethylene glycol) and triethanolamine. In the framework of our investigations, we came to the question whether it is possible to cover the ironoxide NPs by triethanolamine or by triethanolammonium oleate, after NPs' fabrication. This will allow to stabilize NPs, which were fabricated by well-developed co-precipitation routes.

In the present work, we reported our successful fabrication of the novel stabilized triethanolammonium oleate-coated $\mathrm{Fe}_{3} \mathrm{O}_{4} \mathrm{NPs}$, which were fabricated by a traditional approach. It consisted of the aqueous co-precipitation of ferrous and ferric salts using ammonium hydroxide, followed by their stabilization using a mixture of triethanolamine and oleic acid, which react, and triethanolammonium oleate is obtained. We investigated potential application of the produced NPs in theranostics, for example, in magnetic resonance imaging (MRI) and hyperthermia treatment of the cancer cells. The effectiveness of the NPs as the contrast agents for MRI and as the heating agents for hyperthermia was tested ex vivo. We also measured cytotoxicity of the NPs using two colon cell lines: SW480 and SW620, in terms of cell viability (MTT assay) and morphological changes induced in the tumor cells. As a complementary study, we have tested the impact of the $\mathrm{Fe}_{3} \mathrm{O}_{4} \mathrm{NPs}$ on proliferation (population doubling), viability, apoptosis, and oxidative stress of human fibroblasts cultured routinely in clean rooms as advanced therapy medicinal product for the treatment of chronic wounds in order to check biocompatibility and possibility of usage of these particles as supplementary material for fibroblast transplantation and also to assess the possible effect of NPs on fibroblasts present in wound bed and edges.

\section{Experimental}

\section{Synthesis of the $\mathrm{Fe}_{3} \mathrm{O}_{4}$ magnetic NPs}

Materials. Analytical-grade ferric chloride $\left(\mathrm{FeCl}_{3-}\right.$ $\left.6 \mathrm{H}_{2} \mathrm{O}\right)$, ferrous sulfate $\left(\mathrm{FeSO}_{4} \cdot 7 \mathrm{H}_{2} \mathrm{O}\right)$, concentrated ammonia solution, oleic acid, triethanolamine and 
concentrated perchloric acid were used as obtained from Sigma-Aldrich, USA. Distilled water was used throughout these experiments.

Synthesis. Magnetite NPs were obtained by alkaline hydrolysis of iron (II) and iron (III) salts according to the reaction equation:

$\mathrm{Fe}^{2+}+2 \mathrm{Fe}^{3+}+8 \mathrm{OH}^{-} \rightarrow \mathrm{Fe}_{3} \mathrm{O}_{4}+4 \mathrm{H}_{2} \mathrm{O}$

This method is described in detail elsewhere [49-51]. Shortly, to obtain magnetite NPs two salt solutions were prepared: (1) $6 \mathrm{~g}$ of $\mathrm{FeCl}_{3} \cdot 6 \mathrm{H}_{2} \mathrm{O}$ was dissolved in $7.5 \mathrm{ml}$ of distilled water; (2) $10.65 \mathrm{~g}$ of $\mathrm{FeSO}_{4} \cdot 7 \mathrm{H}_{2} \mathrm{O}$ was dissolved in $35 \mathrm{ml}$ of water, while a few drops of concentrated perchloric acid were added to the solution to prevent the oxidation of ferrous ions. Then, the solutions were mixed and filtered on a vacuum filter. The filtered salt solution was poured dropwise into a $200-\mathrm{ml}$ beaker containing $35 \mathrm{ml}$ of $25 \% \mathrm{NH}_{4} \mathrm{OH}$ under continuous stirring with a mechanical stirrer for $15 \mathrm{~min}$. Finally, the precipitate was collected by magnetic field separation and washed several times with distilled water by decantation until the $\mathrm{pH}$ value decreased to 8 .

The stabilization of NPs is made by triethanolammonium oleate, which is prepared by the reaction of $2 \mathrm{ml}$ of oleic acid and $2.5 \mathrm{ml}$ of triethanolamine ( $225 \mu \mathrm{l} / \mathrm{min}$ ) added in portions over $20 \mathrm{~min}$ to the water dispersion of the NPs under the permanent stirring at $50{ }^{\circ} \mathrm{C}$. Then, the obtained mixture was left for resting at the above-mentioned conditions for $2 \mathrm{~h}$. When the stabilization process ended, the resulting colloid was poured to $15-\mathrm{ml}$ flasks and centrifuged at $3000 \mathrm{rpm}$ for $15 \mathrm{~min}$ to separate large NPs from small ones. Because of the weight difference, the large NPs were sedimented at the bottom of the vial during centrifugation, while the small ones stayed in the supernatant. As a result of this process, two types of NPs were obtained: the NPs from supernatant (top NPs) and NPs sedimented at the bottom of the flask (bottom NPs).

\section{TEM characterization}

Scanning transmission electron microscopy (STEM) with the high-angle annular dark-field detector (HAADF) was used for the morphology investigation of the fabricated NPs. The TEM mode was used for selected area electron diffraction (SAED) pattern acquisition. The measurements were taken on an aberration-corrected FEI Titan electron microscope
(FEI Company, USA) operating at $300 \mathrm{kV}$, equipped with a FEG cathode. For the particle size evaluation, the HRSTEM images were taken from different areas of the TEM grids.

\section{Hydrodynamic size characterization}

The hydrodynamic size of the nanoparticles and their agglomerates in water dispersion was measured using a Laser Scattering Particle Size Distribution Analyzer LA-950 Horiba (Japan).

\section{X-ray diffraction}

The crystallographic properties of the NPs were investigated using Bruker D8 Advance X-ray diffractometer (Bruker AXS GmbH, Germany). The measurements were taken in the standard BraggBrentano configuration using $\mathrm{CuK}_{\alpha}$ radiation in the range of $2 \theta$ angles from 20 to $100 \mathrm{deg}$ in steps of $0.02 \mathrm{deg}$. The incident beam was formed by $24-\mathrm{mm}-$ long linear focus and $0.6 \mathrm{~mm}$-wide primary divergence slit. The intensities of diffracted beam were detected using the LynxEye detector (equipped with the Ni filter of $\mathrm{CuK}_{\beta}$ radiation). The XRD patterns were analyzed using FullProf software utilizing the Rietveld refinement method [52]. The peaks were fitted with the use of Thompson-Cox-Hasting [53] pseudo-Voigt profile function, and the background was approached by the 6-coefficient polynomial function.

\section{FTIR measurements}

The Fourier transform infrared spectroscopy (FTIR) measurement was taken using Shimadzu IRAffinity-1 spectrometer (Japan) on water-dispersed top and bottom NPs and on the non-coated iron-oxide NPs. The measurements were taken in the reflection mode at room temperature. All obtained spectra were smoothed with 9 points. The vector normalization and the baseline correction were applied. The obtained spectra were analyzed using OPUS 7.0 software.

\section{Magnetometry}

The magnetic properties of the samples were investigated with a PPMS setup in magnetic fields up to $14 \mathrm{~T}$ and temperature range of $4-300 \mathrm{~K}$ (Cryogenic 
Ltd., USA). The hysteresis curves were measured for dried samples of NPs in a gelatin capsule at temperatures 5 and $300 \mathrm{~K}$, respectively. The zero-field cooled (ZFC) and field cooled (FC) temperature dependences of the magnetization were measured under an applied field of 400 Oe.

\section{Mössbauer spectroscopy}

Mössbauer spectra were recorded in transmission geometry at room temperature and at $16 \mathrm{~K}$, using the MS4 (SEE Co., USA) spectrometer equipped with a ${ }^{57} \mathrm{Co} / \mathrm{Rh}$ source (having the activity of $12 \mathrm{mCi}$ ). Lowtemperature measurements were taken using a closed cycle refrigerator system CCS-850 (Janis Research Company, USA). The temperature was controlled using a LakeShore LS335 temperature controller (Lake Shore Cryotronics, Inc., USA) with dual calibrated DT-670 sensors (an accuracy of \pm $0.005 \mathrm{~K})$. The spectra were fitted using MOSMOD software, assuming a Gaussian distribution of the hyperfine magnetic fields $\left(H_{\mathrm{hf}}\right)$ and quadrupole splitting $(Q S)$ within the iron nuclei. The Lorentzian line shape of the source natural line width was determined from the Mössbauer spectrum of a pure $28-\mu$ m-thick $\alpha$-Fe foil. The spectrometer was calibrated by collecting the spectra for the standard $\alpha-\mathrm{Fe}$ foil at room temperature and at $16 \mathrm{~K}$. All isomer shifts (IS) were presented with respect to the $\alpha$-Fe standard.

\section{The 9.4 T MRI experiments}

The $T_{1}$ and $T_{2}$ relaxation measurements and $\mathrm{MR}$ images were obtained using a $9.4 \mathrm{~T} / 21 \mathrm{~cm}$ magnet (Magnex, UK) and a Bruker console (Bruker, Germany). Standard 5-mm-diameter NMR tubes were used for experiments. A transmit/receive radio frequency (RF) volume birdcage coil was used. A singleslice multi-echo pulse sequence was used for $T 2$ measurements with the following parameters: repetition time (TR) $5 \mathrm{~s}$, echo time (TE) $=4 \mathrm{~ms}, \mathrm{Nr}$ echoes $=128,1$ average, matrix size $128 \times 128$, field of view (FOV) $3 \mathrm{~cm} \times 3 \mathrm{~cm}$, one slice $-2 \mathrm{~mm}$ thick. The $T_{2}$ relaxation time was calculated using a single exponential fitting of the echo train (Bruker, Germany). For $T_{1}$ measurements, Inversion Recovery True FISP method was used with the following parameters: repetition time (TR) within each segment $3 \mathrm{~ms}$, echo time (TE) $1.5 \mathrm{~ms}$, flip angle $15^{\circ}$, matrix size $128 \times 128$, $(\mathrm{FOV}) 3 \mathrm{~cm} \times 3 \mathrm{~cm}$, slice thickness $3 \mathrm{~mm}, 60$ frames (96 ms apart) $\times 4$ segments. Sixty data points on the recovery curve were used for the fitting. The standard mono-exponential fitting (Bruker, Germany) method was applied for $T_{1}$.

The $1 / T_{1}$ and $1 / T_{2}$ times of both top and bottom NPs concentrations were plotted against their concentrations, [CA]. The slope of the linear fit provided $r_{1}$ and $r_{2}$ relaxivities according to the equation:

$\frac{1}{T_{i}}=\frac{1}{T_{i}^{0}}+r_{i}[C A], \quad i=1,2$

where $T_{i}$ is the $T_{1}$ and $T_{2}$ relaxation time at particular concentration of NPs [CA], $T_{i}^{0}$ is the relaxation time of the solution without NPs.

\section{Heating rate dependence measurements and specific loss power calculations}

The measurements of the heating rates were taken in a glass vial $(2 \mathrm{~mL})$ using a home-built induction heating unit (Częstochowa University of Technology, Poland) with a 100-mm-diameter (8 turns) heating coil. The temperature of the coil was controlled by a cooling system with circulating water. The magnetic field generated in the induction heating coil was controlled using the Rogowski coil. Glass vial containing the NPs dispersion was thermally isolated from the induction heating coil and situated in its center. The temperature of the dispersion was measured using the T-type micro-thermocouple.

For the measurement, a $5 \mathrm{wt}$.\% dispersions of ironoxide NPs in glycerol have been used. The measurements of the heating rates were taken on $5 \mathrm{wt} . \%$ dispersions of iron-oxide NPs in glycerol. The glycerol was used as a liquid medium for measurement of the heating efficiency of magnetite nanoparticles, in order to eliminate or significantly reduce the contribution of Brownian relaxations in alternating magnetic field of frequency $100 \mathrm{kHz}$, due to its high viscosity [54]. The specific loss power (SLP) was calculated for both the top and the bottom NP dispersions using the formula:

$\mathrm{SLP}=\frac{C}{m_{\mathrm{Fe} 3 \mathrm{O} 4}} \frac{d T}{d t}$

where $m_{\mathrm{Fe} 3 \mathrm{O} 4}$-the mass of the magnetite NPs dispersed in glycerol, $T$-temperature, $t$-time. The heat capacity of the dispersion $(C)$ was calculated using the formula: 
$C=\sum_{i=1}^{n} c_{i} m_{i}$

where $c_{i}$-are the specific heat capacities of glycerol $(2.434 \mathrm{~J} /(\mathrm{g} \mathrm{K}))$ and magnetite NPs $(0.62 \mathrm{~J} /(\mathrm{g} \mathrm{K}))$, while $m_{i}$-are the masses of glycerol and magnetite NPs, respectively.

\section{Cell lines and MTS assay}

Two human colon cell lines (SW480 and SW620) were used as an in vitro model. These cell lines were cultured in DMEM cell culture medium with high glucose (Corning, NY, USA) in a $37^{\circ} \mathrm{C}$ humidified atmosphere with $5 \%$ of $\mathrm{CO}_{2}$. All media were supplemented with $10 \%$ fetal bovine serum (FBS, Biowest, Nuaille, France) and gentamicin $(50 \mu \mathrm{g} / \mathrm{ml})$, (PAN-Biotech, Aidenbach, Germany). The cells were cultured by biweekly passages and were regularly tested for Mycoplasma sp. contamination by PCR-ELISA kit (Roche, Mannheim, Germany) according to the manufacturers' instruction. Moreover, for determining the effect of NPs on cells' proliferation, the3-(4,5-dimethylthiazol-2-yl)-5-(3-carboxymethoxyphenyl)-2-(4-sulfophenyl)-2H-tetrazolium (MTS) assay (CellTiter 96® AQueous One Solution Cell Proliferation Assay, Promega, Madison, WI, USA) was performed. Briefly, the cells were cultured on the flatbottom 96-well plates (Sarstedt, Numbrecht, Germany) at a density $1 \times 10^{4} /$ well in DMEM medium containing $10 \%$ FBS. After $24 \mathrm{~h}$, the $10 \mu \mathrm{l}$ of NPs solutions having the concentrations of $5 \mu \mathrm{g} / \mathrm{ml}, 50 \mu \mathrm{g} / \mathrm{ml}$ and $100 \mu \mathrm{g} / \mathrm{ml}$ was added to the cells. After additional $3 \mathrm{~h}$ and $24 \mathrm{~h}$ of culture, the $20 \mu \mathrm{l}$ of MTS (CellTiter $96{ }^{\circledR}$ AQueous One Solution Cell Proliferation Assay, Promega, USA) dye solution was added per well and incubated for $3 \mathrm{~h}$. The quantity of formazan product, directly proportional to the number of living cells in culture, was detected by absorbance measurements at $490 \mathrm{~nm}$ with a 96-well plate reader (Spark ${ }^{\circledR}$ Tecan, Mannedorf, Switzerland). The obtained MTS assay results are represented as the average values from three parallel wells \pm SEM (the standard deviation). The quantitative results were compared with the $T$-test. $P$ value (probability of obtaining test results) $<0.05$ was considered to be statistically significant.

\section{Fibroblast cell line studies}

Requirements for human cell culturing according to GMP guidelines were described before [19]. Cells' culture (fibroblasts) was carried out in a tissue bank clean room (GMP class C; ISO class 7) under laminar low cabinet conditions (GMP class A; ISO class 4.8; HSKS 18, thermo).

After $24 \mathrm{~h}$ and $48 \mathrm{~h}$, the color of medium was checked and plates were observed under microscope (Nikon) for evidence of any contamination. If the medium has changed its color, it indicated bacterial contamination. Samples from every plate were taken for microbiological testing with protocol described by us before [55].

To analyze the multiplicity of population doubling (PD), the cells were detached from the surface of cell culture bottle by digestion (using TrypLE Select Enzyme $(1 \times)$ by Thermo Fisher Scientific) after 7 days and compared with the number of seeded cells. The doubling time of population was calculated using earlier presented [56] formula:

$\mathrm{PD}=\frac{\left(\log N_{h}-\log N_{0}\right)}{\log (2)}$

where $N_{h}$ is the number of cells on the day of the end of the growth of the cell culture, $N_{0}$ is the cell-seeding number.

The analysis of apoptosis and percentage of dead cells were performed using The Tali ${ }^{\circledR}$ Apoptosis Kit. Cells were seeded in a 24-well plate at a density of 100,000 cells/well. The experiment was performed in accordance with the manufacturer's protocol. For analysis, the cells were detached from the plate (TrypLE $^{\mathrm{TM}}$ Select $(1 \times)$, Phenol Thermo Fisher Scientific) at the seventh day of the culture.

The analysis of oxidative stress was performed using The CellROX ${ }^{\mathrm{TM}}$ Green Reagent, for oxidative stress detection. The experiment was performed in accordance with the manufacturer's protocol. For analysis, the cells were detached from the plate TrypLE $^{\mathrm{TM}}$ Select $(1 \times)$, Phenol Thermo Fisher Scientific) at the seventh day of the culture. 


\section{Results and discussion}

\section{Morphology, phase composition and magnetic properties of NPs}

The morphology investigation of the fabricated NPs was observed using the transmission electron microscopy (Fig. 1) (methodology described in the paragraph 2.2). The images for the top NPs (which were in supernatant after centrifugation) and the bottom NPs (which sedimented at the bottom of the vial after centrifugation) are presented in Fig. 1a and $b$, respectively. In order to find the size distributions of the NPs, the measurements of their sizes were taken using many different images taken from different areas of the TEM grids. We have selected images of only these NPs, which were separated and clearly visible in images of their aggregates. From the size distributions (Fig. 1c and 1d), one can see that the morphology of the top NPs differs from the bottom NPs in more uniform sizes around $11 \mathrm{~nm}$, while the bottom NPs have an average diameter around $19 \mathrm{~nm}$ and much wider size distribution (from 7 to $50 \mathrm{~nm}$ ). The shapes of fabricated NPs are close to spherical. Both types of NPs have shown a tendency to form aggregates due to their inherent magnetism and Van der Waals forces. Therefore, as can be seen from the TEM images, the NPs form clusters, which consists of aggregates of a few NPs. The particle size distribution measured for the bottom NPs suggests the presence of relatively large fraction of NPs of similar sizes to those for the top NPs. This is inevitable due to their aggregation with nanoparticles of larger sizes and their subsequent sedimentation during centrifugation. However, this fact does not significantly impact their performance in the magnetic field and in contact with cells. The SAED pattern of the bottom NPs (Fig. 1e) with clearly visible diffraction rings demonstrates the highly crystalline nature of the fabricated NPs. The diffraction rings were indexed to the (220), (311), (400), (422), (511) and (400) lattice diffractions of the $\mathrm{Fe}_{3} \mathrm{O}_{4}$ phase with inverse spinel crystal structure.

The hydrodynamic size histograms of the top and bottom NPs (Fig. 2) were obtained from Laser Scattering Particle Size Distribution Analyzer (LA-950 Horiba) measurements. According to these histograms, top NPs formed small agglomerates with mean hydrodynamic sizes of $80 \mathrm{~nm}$, where bottom NPs formed larger agglomerates with mean hydrodynamic sizes of $170 \mathrm{~nm}$. Therefore, both the top NPs and the bottom NPs are suitable for imaging or drug
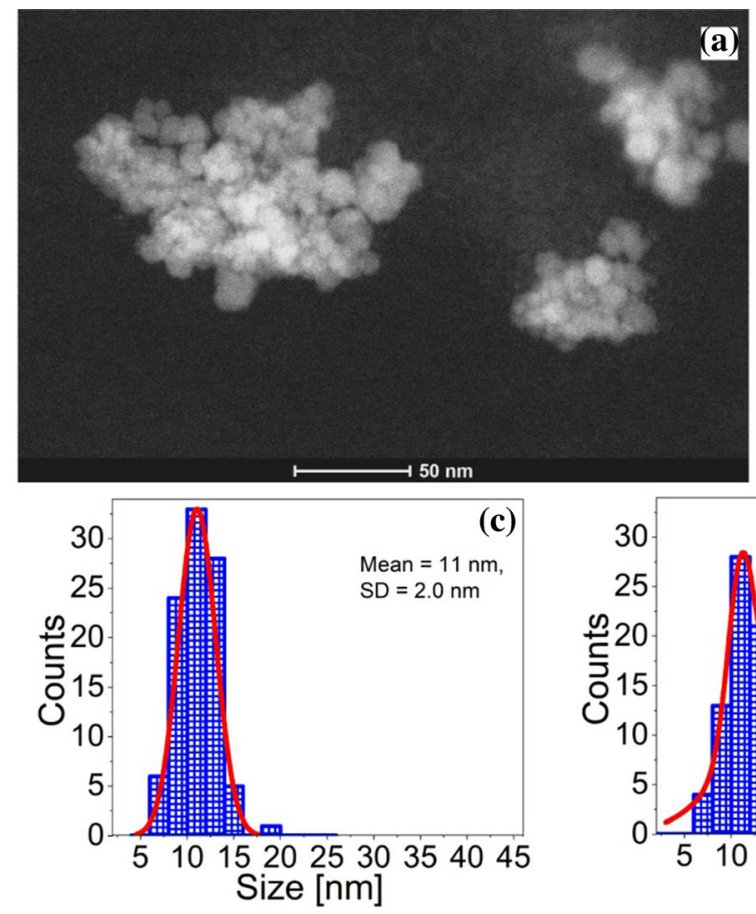

a)
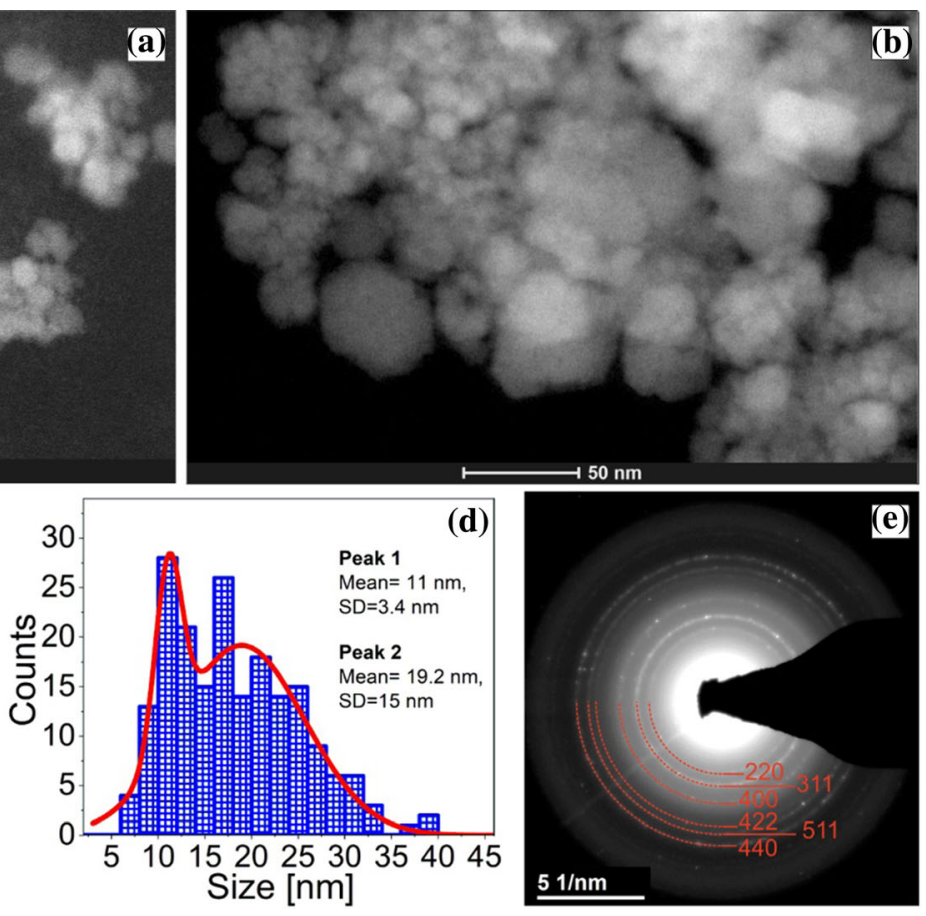

Figure 1 HAADF STEM overview of $\mathbf{a}$ the top and $\mathbf{b}$ the bottom NPs; the size distributions of $\mathbf{c}$ the top NPs and $\mathbf{d}$ the bottom NPs were obtained by analysis of the TEM images; e SAED pattern of the bottom NPs. 


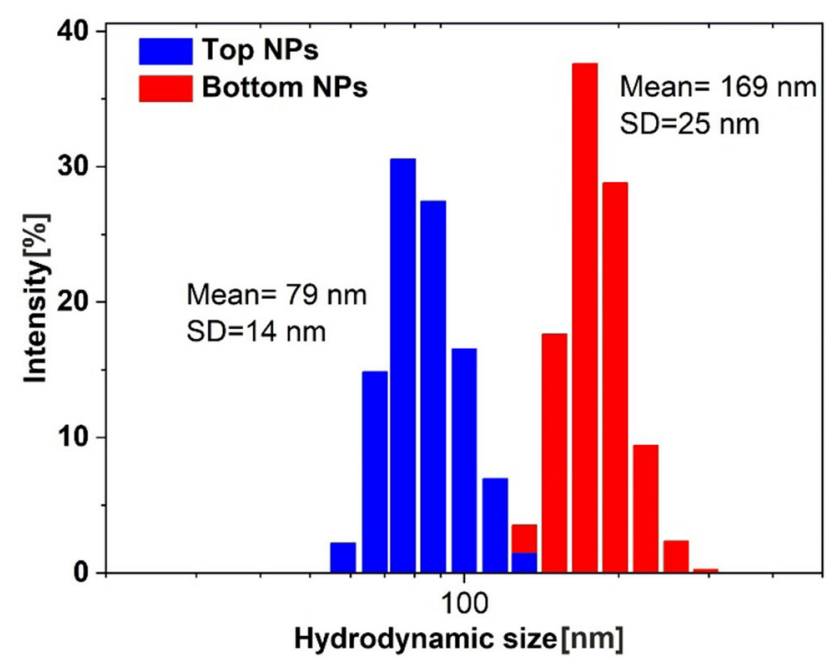

Figure 2 Hydrodynamic particle size distributions of the top and the bottom NPs in water dispersion.

delivery to liver and spleen. They also can become an alternative to the FDA-approved AMI-25 contrast agent. Moreover, the top NPs can be used for blood pool and be an alternative to SHU 555A contrast agent [57].

XRD patterns of the top and the bottom NPs are presented in Fig. 3. Both XRD patterns indicated high crystallinity of the investigated NPs. For both types of NPs, the observed diffraction peaks are well indexed and can be assigned to the magnetite $\left(\mathrm{Fe}_{3} \mathrm{O}_{4}\right)$ or to the maghemite $\left(\gamma-\mathrm{Fe}_{2} \mathrm{O}_{3}\right)$ phases, which have the same cubic spinel crystal structure and positions of their

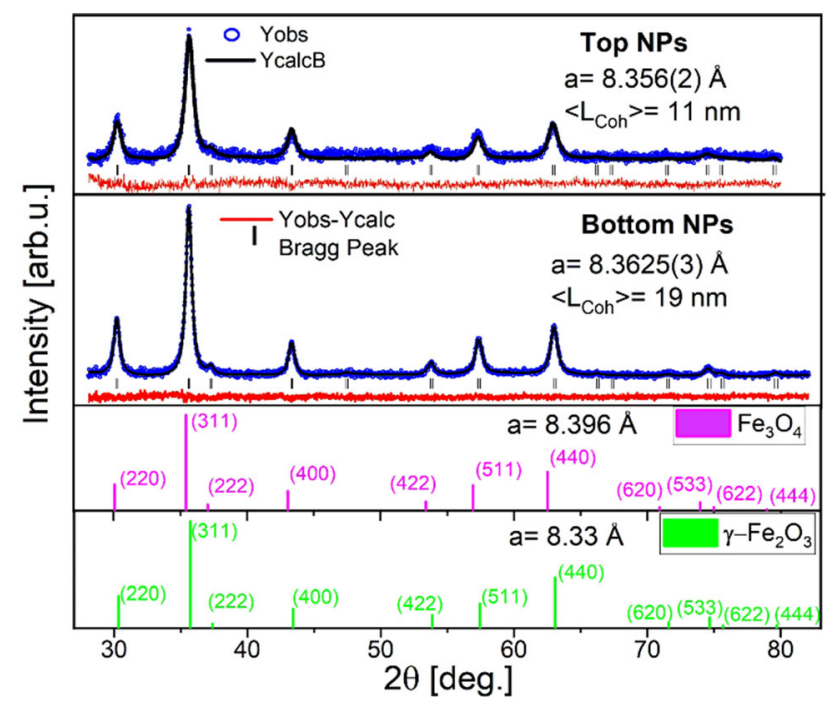

Figure 3 XRD patterns for the top NPs and the bottom NPs. On the bottom of the image, the standard references for the $\mathrm{Fe}_{3} \mathrm{O}_{4}$ [58] and $\gamma-\mathrm{Fe}_{2} \mathrm{O}_{3}[59,60]$ are presented. diffraction peaks are almost identical. We can determine the crystal structure of the NPs based on the lattice parameter values. The calculated lattice constants for the top NPs $(a=8.356(2) \AA)$ and for the bottom NPs $(a=8.3625(3) \AA)$ are lower than this for the bulk magnetite $(a=8.396 \AA$ ) [58]. This can be explained by the surface oxidation of the NPs, where the oxygen atoms diffuse into the crystal lattice and cause the phase transformation on the surface of the NPs. The unit cell parameters calculated for the investigated specimens are more coherent with those characteristic for the maghemite $\gamma-\mathrm{Fe}_{2} \mathrm{O}_{3}[59,60]$, which lattice constant $(a=8.33 \AA)$ is smaller than this for the magnetite $(a=8.396 \AA)$. As a result, the average value of the lattice constant depends on the scale of interplay between the two crystal phases in the NPs. Since the maghemite is mainly present at the surface of the particles, for the smaller NPs this maghemite layer plays a greater role in the total volume fraction. Thus, its impact on the average lattice constant is greater for the smaller NPs (top NPs). For this reason, calculated average lattice constant for the top NPs is smaller than this for the larger ones (bottom NPs). The Rietveld refinement performed using FullProf allowed to calculate the average coherent scattering lengths for the Top $\left(\left\langle\mathrm{L}_{\mathrm{Coh}}\right\rangle \approx\right.$ $9 \mathrm{~nm})$ and the Bottom $\left(\left\langle\mathrm{L}_{\mathrm{Coh}}\right\rangle \approx 13 \mathrm{~nm}\right) \mathrm{NPs}$, which we assumed to be equal to the average crystallite sizes. The obtained values are in a good agreement with the TEM results, where the larger values of $\left\langle\mathrm{L}_{\mathrm{Coh}}\right\rangle$ correspond to NPs with larger average sizes.

The stabilization of the NPs by coating occurs when triethanolammonium oleate molecules cover the surface of the NPs. Triethanolammoium oleate is formed when the mixture of triethanolamine and oleic acid is added to the water dispersion of NPs at elevated temperature $\left(50{ }^{\circ} \mathrm{C}\right)$. It is a well-known reaction explained in detail elsewhere [61]. To obtain information about molecular structure of the coating as well as interactions between coating and iron-oxide NPs core, the Fourier transform infrared spectroscopy (FTIR) measurement was taken. For this purpose, transmittance spectra of $\mathrm{Fe}_{3} \mathrm{O}_{4}$ magnetic nanoparticles without and with triethanolammonium oleate coating were measured (Fig. 4).

The triethanolammonium oleate attaches directly to the precipitated NPs via bonding between $\mathrm{OH}$ groups contained in the amine functional group of the coating and the Fe-OH on the surface of the NPs. The colloidal stability is achieved by steric repulsion. 


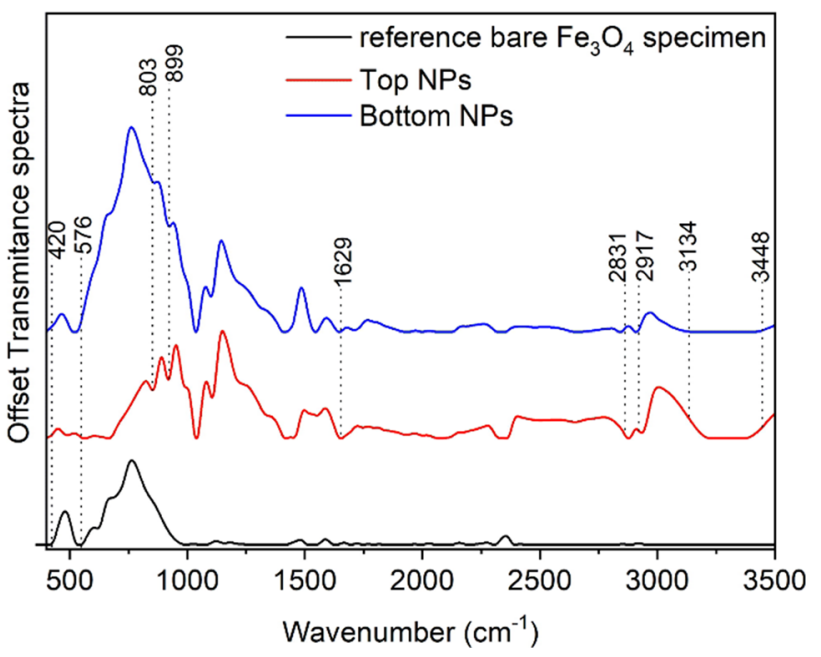

Figure 4 FTIR spectra of $\mathrm{Fe}_{3} \mathrm{O}_{4}$ magnetic nanoparticles without triethanolammonium oleate (black spectrum) and with triethanolammonium oleate-top NPs (red spectrum), bottom NPs (blue spectrum).

When we compared the obtained FTIR spectra for bare $\mathrm{Fe}_{3} \mathrm{O}_{4}$ NPs (not coated with triethanolammonium oleate-black spectrum) and with those coated with triethanolammonium oleate-top NPs (red spectrum) and bottom NPs (blue spectrum), some differences in the peaks were visible. In all-obtained FTIR spectra, the peaks corresponding to the $\mathrm{Fe}-\mathrm{O}$ vibration bonds of the $\mathrm{Fe}_{2} \mathrm{O}_{3}$ were visible at $420 \mathrm{~cm}^{-1}$ and $576 \mathrm{~cm}^{-1}$ [62]. The second peak was shifted in the spectra of top and bottom NPs, which can be caused by coating of NPs with triethanolammonium oleate. However, in spectra obtained for coated NPs (top and bottom NPs) some additional peaks were noticed. The peaks corresponding to wavenumbers: $899 \mathrm{~cm}^{-1}$ and $803 \mathrm{~cm}^{-1}$ originate from out-of-plane $\mathrm{C}-\mathrm{H}$ vibrations caused by the remnant triethanolammonium oleate on the surface of iron-oxide NPs, while the peaks around $1629 \mathrm{~cm}^{-1}$ were assigned to the vibrations of $\mathrm{C}-\mathrm{N}$ bonds [63]. Moreover, the peaks at $2831 \mathrm{~cm}^{-1}$ and $2917 \mathrm{~cm}^{-1}$ correspond to $\mathrm{CH}_{3}$ symmetric and asymmetric vibrations from triethanolammonium oleate and the peaks at $3134 \mathrm{~cm}^{-1}$ were assigned to the $v(\mathrm{~N}+-\mathrm{H})$ vibrations from these chemical compound [64]. Furthermore, signal from $\mathrm{O}-\mathrm{H}$ stretching vibrations of absorbed water was noticed at $3448 \mathrm{~cm}^{-1}$ [63].

Magnetic measurements were taken to investigate the magnetic properties of the top and the bottom NPs. Hysteresis loops recorded at $5 \mathrm{~K}$ and $300 \mathrm{~K}$ for both types of NPs are presented in Fig. 5. Both the top and the bottom $\mathrm{Fe}_{3} \mathrm{O}_{4}$ NPs reveal zero hysteresis losses and zero magnetization remanence $\left(\mathrm{M}_{\mathrm{r}}\right)$ at $300 \mathrm{~K}$, which means that both NPs are superparamagnetic at room temperature. The values of saturation magnetization $\left(\mathrm{M}_{\mathrm{s}}\right)$ at 5 and $300 \mathrm{~K}$ for the top $\left(\mathrm{M}_{\mathrm{s}}(5 \mathrm{~K})=58 \mathrm{emu} / \mathrm{g}\right.$ and $\left.\mathrm{M}_{\mathrm{s}}(300 \mathrm{~K})=51 \mathrm{emu} / \mathrm{g}\right)$ and the bottom $\left(\mathrm{M}_{\mathrm{s}}(5 \mathrm{~K})=52 \mathrm{emu} / \mathrm{g}\right.$ and $\mathrm{M}_{\mathrm{s}}(300 \mathrm{~K})$ $=45 \mathrm{emu} / \mathrm{g}$ ) NPs were lower than the $\mathrm{M}_{\mathrm{s}}$ for the reference bulk magnetite at room temperature (92 emu/g) [65-67] and also for unstabilized magnetite NPs of similar sizes [68]. Moreover, the values of $\mathrm{M}_{\mathrm{s}}$ are larger than these measured for SPIONs produced by thermal decomposition, encapsulated in $\mathrm{SiO}_{2}\left(\mathrm{M}_{\mathrm{s}}=15 \mathrm{emu} / \mathrm{g}\right.$ [36] $)$ and larger than $\mathrm{M}_{\mathrm{s}}$ measured for USPIONs $(5 \mathrm{~nm})$ coated with the cystine shell $(30 \mathrm{emu} / \mathrm{g}$ [38]). Also, these values coincide well with $\mathrm{M}_{\mathrm{s}}$ (52 emu/g) measured for the iron-oxide NPs produced by co-precipitation method and the subsequent functionalization [69], showing high efficiency in hyperthermia treatment. The $M_{s}$ values are normalized to the mass of the nanoparticles, which includes the mass of the bare magnetite NPs and the mass of the surfactant shell, which stabilize them. The surfactant contributes to the overall weight of the sample and thus affects the measured saturation magnetization. Also, as it was shown by Haracz et al. [70], the organic ligands can change the magnetic moment on the surface of NPs, which leads to differences in magnetic properties of the same NPs covered with the different coatings. On the other hand, the presence of the surfactant layer stabilizes the dispersions of NPs. The influence of surfactant (a layer of triethanolammonium oleate used for NPs stabilization, adsorbed on the surface of the NPs) on the values of $\mathrm{M}_{\mathrm{s}}$ for the bottom NPs was more pronounced. This is because the excess of the unadsorbed surfactant on the surfaces of NPs was deposited on the bottom NPs during centrifugation and was hard to be washed out. Although the values $\mathrm{M}_{\mathrm{s}}$ for the top and the bottom NPs are lower than those for the reference magnetite specimen, they are still high enough to make them promising in application for both diagnosis and treatment with hyperthermia. In case of MRI, a high value of $\mathrm{M}_{\mathrm{s}}$ causes strong magnetic field perturbations, hence fast proton dephasing, which leads to shortening of $T_{2}$ (transverse or spin-spin) relaxation time of the neighboring regions [71]. Furthermore, NPs with high $\mathrm{M}_{\mathrm{s}}$ provide high heating power, which can be delivered by a minimal amount of material during hyperthermia 
Figure 5 The hysteresis loops of $\mathbf{a}$ the top and $\mathbf{b}$ the bottom $\mathrm{Fe}_{3} \mathrm{O}_{4}$ NPs measured at $5 \mathrm{~K}$ and $300 \mathrm{~K}$. The insets are an expanded view of the low-field region; ZFC-FC curves of $\mathrm{c}$ the top and $\mathbf{d}$ the bottom NPs; e the bottom NPs without magnetic field (left) and attracted by the magnet (right).
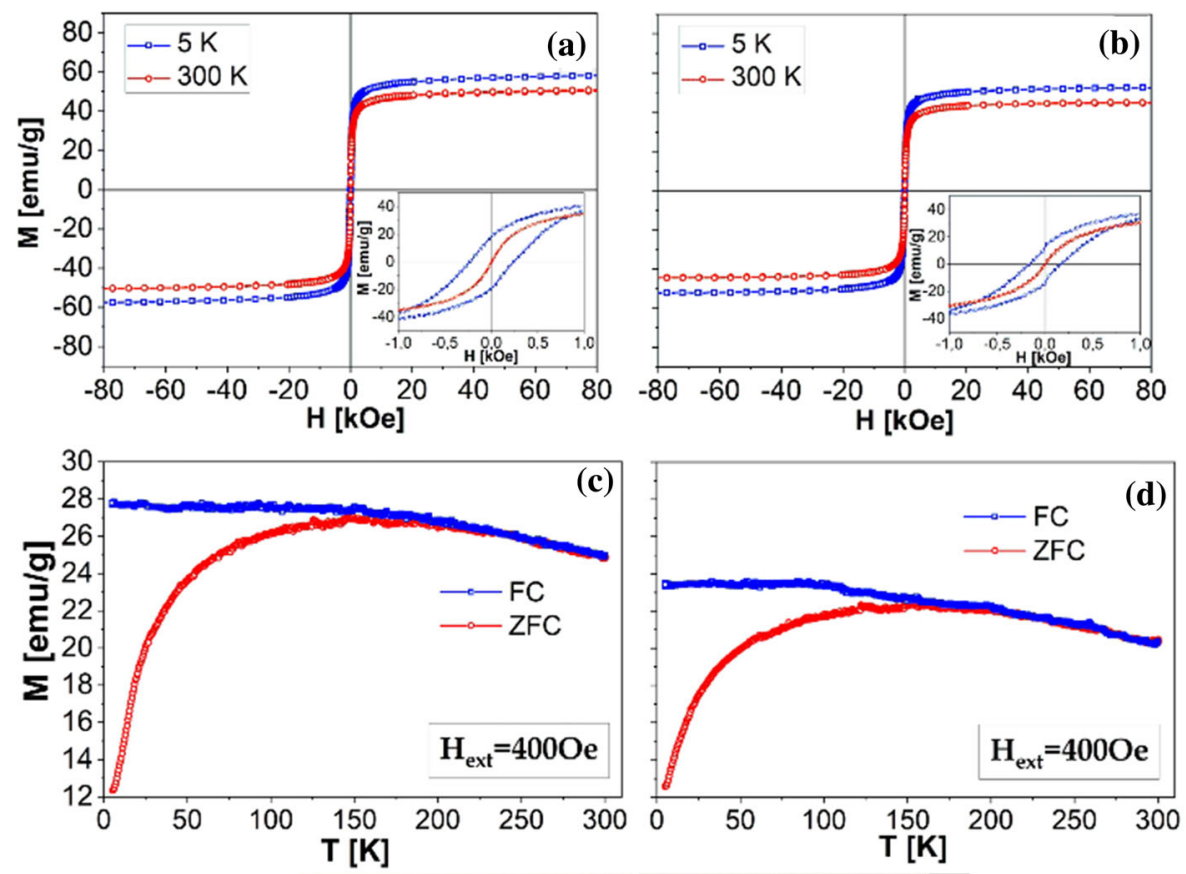

(e) therapy $[10,39,72]$. At $5 \mathrm{~K}$, the reversal of the NPs magnetic moments is limited; thus, the magnetic measurements clearly have shown ferrimagnetic behavior of the NPs. The coercive field of the top NPs was larger than this for the bottom NPs ${ }_{j} H_{C}=240$ Oe for the top NPs and ${ }_{J} H_{C}=170 \mathrm{Oe}$ for the bottom NPs). Lower ${ }_{\mathrm{J}} \mathrm{H}_{\mathrm{C}}$ for the bottom NPs can be attributed to the larger dipolar interparticle interactions that favors the demagnetization process [73, 74].

Figure $5 c$ and $d$ shows the temperature dependence of the magnetic moment $\mathrm{M}(\mathrm{T})$ for the top and the bottom NPs under an applied magnetic field $\left(H_{\text {ext }}=400\right.$ Oe) after zero-field cooling (ZFC) and after field cooling (FC). The feature of the ZFC-FC curves confirmed that both the top and the bottom NPs are superparamagnetic in their nature with the blocking temperatures $T_{B}$ at around $135 \mathrm{~K}$ and bifurcation temperature $T_{b f}$ (temperature where the ZFC and FC curves split) around 220-230 K. According to Plouffe et al. [75], a broad peak on ZFC curve indicates a presence of wide particle size distributions of NPs. The top and bottom NPs have almost similar $T_{B}$ and $T_{b f}$, which indicates their similar magnetic ordering at low temperature and superparamagnetic behavior above $135 \mathrm{~K}$ [76].

Also, it should be mentioned that the top and the bottom NPs make a stable uniform colloid (with the maximum studied concentration of about $0.1 \mathrm{~g} / \mathrm{mL}$ ), which did not sediment for several months. In the presence of magnetic field, the top and the bottom NPs in low concentration dispersions can be condensed in a small area (see Fig. 5e), leaving the bulk solution clear and transparent.

Mössbauer spectra were measured for the top and bottom NPs at $16 \mathrm{~K}$ and at $300 \mathrm{~K}$. This technique was used as a complementary study to the XRD and magnetometry. It allows to characterize local structure, phase composition and the oxidation state of iron ions in NPs. Also, due to its short relaxation time $\left(\approx 10^{-8} \mathrm{~s}\right)$, the Mössbauer spectroscopy allows to 
understand better the nature of observed magnetic properties of NPs in the processes of local hyperthermia treatment and/or MRI diagnostics [77, 78].

Experimental Mössbauer spectra together with their fits are presented in Fig. 6. The parameters of hyperfine interactions extracted from fitted subspectra are summarized in Table 1. It was shown that Mössbauer spectrum measured for the top NPs at $300 \mathrm{~K}$ has a shape of magnetically collapsed sextet with broadened lines not allowing its reliable fit. However, when it was measured at $T=16 \mathrm{~K}$, this spectrum transformed into the well magnetically split sextet, successfully fitted by superposition of three magnetic subspectra with hyperfine parameters well corresponding to the $\mathrm{Fe}_{3} \mathrm{O}_{4}$ NPs $[78,79]$. In particular, the sextet (area contribution of 53\%) with the IS = $0.27 \mathrm{~mm} / \mathrm{s}$ and the $H_{\mathrm{hf}}=50.0 \mathrm{~T}$ corresponds to the $\mathrm{Fe}^{3+}$ ions at tetrahedral sites $\left(\mathrm{Fe}^{3+}{ }_{\text {tetra }}\right)$. Two other sextets-one with the $I S=0.37 \mathrm{~mm} / \mathrm{s}$ and $H_{\mathrm{hf}-}$ $=51.4 \mathrm{~T}$ and another with $I S=0.70 \mathrm{~mm} / \mathrm{s}$ and $H_{\mathrm{hf}-}$ $=42.1 \mathrm{~T}$-are assigned to $\mathrm{Fe}^{3+}\left(\mathrm{Fe}^{3+}{ }_{\text {octa }}\right)$ and $\mathrm{Fe}^{2+}$ $\left(\mathrm{Fe}^{2+}{ }_{\text {octa }}\right)$ ions at octahedral sites, correspondingly. Observed transformation of magnetically collapsed sextet at $300 \mathrm{~K}$ toward resolved magnetic sextet at $16 \mathrm{~K}$ obviously proves the sufficient contribution of nanoparticles that demonstrate superparamagnetic relaxation at room temperature. This effect well correlates with the outcome of the magnetometry (see
Fig. 6a and 6c). This observation is also in a good agreement with the TEM and XRD data, confirming the formation of NPs having the average diameter of 9-11 nm, that is way below the threshold of superparamagnetic state for the $\mathrm{Fe}_{3} \mathrm{O}_{4} \mathrm{NPs}$ at room temperature [80].

For the bottom NPs, the magnetic-split Mössbauer spectra were measured both at $300 \mathrm{~K}$ and $16 \mathrm{~K}$. At room temperature, the best possible fit represents superposition of two sextets, characteristic for $\mathrm{Fe}^{3+}$ tetra ions (IS $=0.31 \mathrm{~mm} / \mathrm{s} ; H_{\mathrm{hf}}=47.8 \mathrm{~T}$ ) and $\mathrm{Fe}^{3+}{ }_{\text {octa }}$ $\left(I S=0.40 \mathrm{~mm} / \mathrm{s} ; H_{\mathrm{hf}}=42.5 \mathrm{~T}\right)$ in $\mathrm{Fe}_{3} \mathrm{O}_{4}$ phase. Furthermore, the spectrum measured at $T=16 \mathrm{~K}$ for the bottom NPs was successfully fitted with three subspectra, typical for the $\mathrm{Fe}_{3} \mathrm{O}_{4}$ phase. As was evidenced in the data collected in Table 1, fitted parameters for the top and the bottom NPs at $T=16 \mathrm{~K}$ are very close, thus confirming the correctness of applied fitting model.

It is worth noticing that contribution from the $\mathrm{Fe}^{2+}{ }_{\text {octa }}$ decreases for top NPs as compared to bottom NPs. This effect could be attributed to a partial oxidation of NPs, leading to the formation of maghemite $\gamma-\mathrm{Fe}_{2} \mathrm{O}_{3}$ on the surface of both types of NPs.

The time window for the detection of the Mössbauer effect is defined by the Larmor precession period, which in the ${ }^{57} \mathrm{Fe}$ nucleus is about $10 \mathrm{~ns}$. The outcome of the Mössbauer spectra measurement
Figure 6 Mössbauer spectra of the top (a, c) and the bottom $(\mathbf{b}, \mathbf{d})$ NPs, which were measured $16 \mathrm{~K}(\mathbf{a}, \mathbf{b})$ and at room temperature $(\mathbf{c}, \mathbf{d})$.
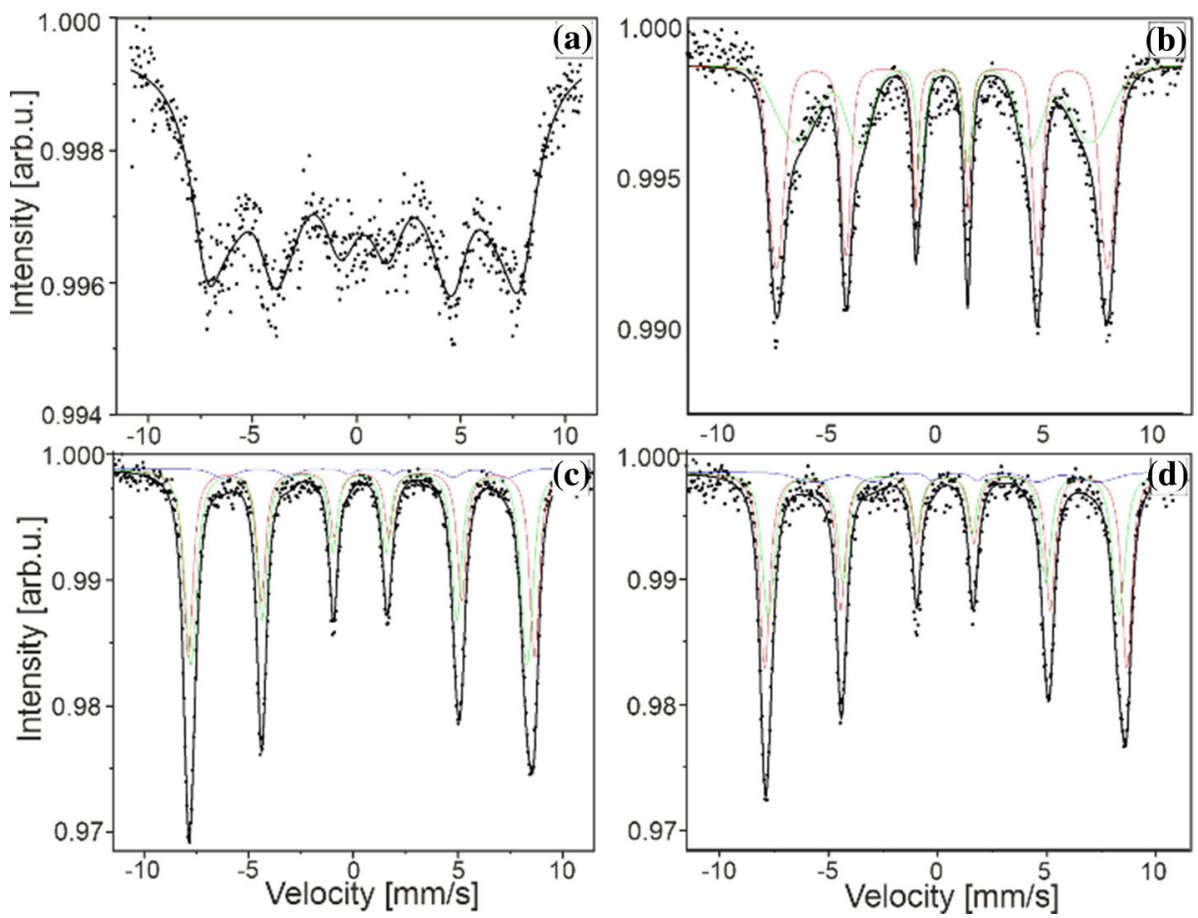
Table 1 Fitting parameters of Mössbauer spectra approximation

\begin{tabular}{|c|c|c|c|c|c|c|}
\hline Sample (temperature) & Sub-spectrum & $I S, \mathrm{~mm} / \mathrm{s}$ & $H_{\mathrm{hf}}, \mathrm{T}$ & $H_{\mathrm{hf}}$-Sigma, $\mathrm{T}$ & $Q S, \mathrm{~mm} / \mathrm{s}$ & Area ratio, $\%$ \\
\hline Top $\mathrm{Fe}_{3} \mathrm{O}_{4} \mathrm{NPs}$ & $\mathrm{Fe}^{3+}{ }_{\text {tetra }}$ & 0.27 & 50.0 & 1.0 & -0.01 & 53 \\
\hline \multirow[t]{2}{*}{$(16 \mathrm{~K})$} & $\mathrm{Fe}^{3+}{ }_{\text {octa }}$ & 0.37 & 51.4 & 0.5 & 0.00 & 43 \\
\hline & $\mathrm{Fe}^{2+}{ }_{\text {octa }}$ & 0.70 & 42.1 & 2.6 & -0.14 & 4 \\
\hline \multirow[t]{2}{*}{ Down $\mathrm{Fe}_{3} \mathrm{O}_{4}$ NPs $(300 \mathrm{~K})$} & $\mathrm{Fe}^{3+}$ tetra & 0.31 & 47.8 & 1.8 & 0.01 & 52 \\
\hline & $\mathrm{Fe}^{3+}$ octa & 0.40 & 42.5 & 5.5 & -0.02 & 48 \\
\hline \multirow[t]{3}{*}{ Down $\mathrm{Fe}_{3} \mathrm{O}_{4}$ NPs $(16 \mathrm{~K})$} & $\mathrm{Fe}^{3+}{ }_{\text {tetra }}$ & 0.28 & 49.9 & 0.9 & -0.02 & 43 \\
\hline & $\mathrm{Fe}^{3+}{ }_{\text {octa }}$ & 0.35 & 51.5 & 0.5 & 0.01 & 50 \\
\hline & $\mathrm{Fe}^{2+}$ octa & 0.80 & 40.3 & 4.4 & 0.02 & 7 \\
\hline
\end{tabular}

$H_{\mathrm{hf}}$-hyperfine magnetic fields, $Q S$ — quadrupole splitting, $I S$ —isomer shifts

depends on the magnetic state of the Fe atoms. For the superparamagnetic nanoparticles, the spin fluctuation time can be comparable or less than the Larmor precession period. In such case, the Mössbauer spectrum consists of the doublet line similar to this for the paramagnetic specimen [81]. For larger ferrimagnetic nanoparticles and agglomerates of small magnetically interacting NPs, the fluctuation time is longer than $10 \mathrm{~ns}$; thus, the sextet lines are detected. The Mössbauer spectrum measured for the bottom NPs at room temperature is typical for the specimens with ferrimagnetic ordering evidenced by the presence of well-pronounced Mössbauer spectrum, which can be fitted with the use of two sextet lines (Fig. 6d). This also has its consequence in the behavior of the bottom NPs in the alternating magnetic field (AMF) of the frequency $100 \mathrm{kHz}$. The majority of the NPs (or rather their agglomerates) respond collectively to AMF, which results in hysteresis losses and thus their intensive heating. On the other hand, the noisy Mössbauer spectrum with less pronounced sextet for the top NPs comes from the presence of large fraction of non-agglomerated superparamagnetic particles. In such case, the magnetic moment undergoes reorientation at times around $10 \mathrm{~ns}$. For this specimen, one can expect lower hysteresis losses when subjected to the $100 \mathrm{kHz}$ alternating magnetic field.

\section{MR Relaxation measurements and MR imaging of the top and the bottom NPs}

Changes in $T_{2}$ and $T_{1}$ relaxation times due to the presence of NPs were demonstrated by collecting the $T_{2}$ - and $T_{1}$-weighted MRI for phantoms with different concentrations of NPs. The initial concentrations of the top and the bottom NPs $(10.8 \mathrm{mg} / \mathrm{ml})$ were diluted 50, 100 and 250 times, corresponding to $0.22 \mathrm{mg} / \mathrm{ml}, \quad 0.11 \mathrm{mg} / \mathrm{ml}$ and $\quad 0.04 \mathrm{mg} / \mathrm{ml}$, respectively.

Figure 7 shows images of phantoms with various concentrations of NPs obtained with SE and Inversion Recovery TRUE FISP pulse sequences, respectively. With the decrease of concentration, obvious lightening of $T_{2}$-weighted MRI (Fig. 8a) and darkening of $T_{1}$-weighted MRI (Fig. $7 \mathrm{~b}$ ) were observed for both types of NPs. Figure 8 shows relationship between relaxation times and concentrations of NPs. From Fig. 8a, a linear increase of $T_{2}$ with decrease of the NPs concentrations can be seen. Also, linear relationships can be found for $T_{1}$, where $T_{1}$ increases with decreasing concentrations of the top and the bottom NPs. Therefore, the higher the concentration of NPs, the stronger the reduction of $T_{2}$ and $T_{1}$ relaxation times can be observed. These results indicate that both types of NPs can be used as contrast agents for $T_{2^{-}}$and $T_{1}$-weighted MRI. As seen, the larger NPs (bottom) reduce relaxation time more than smaller NPs (top).

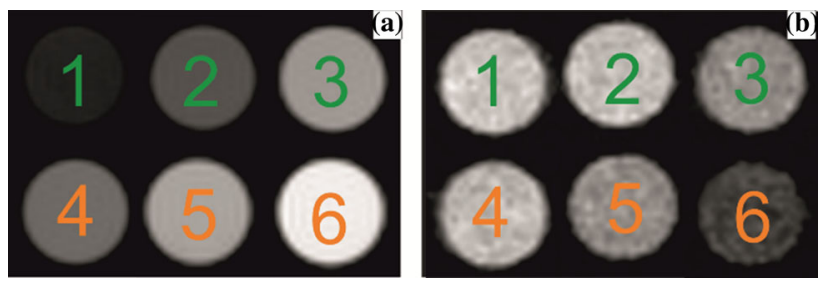

Figure 7 a An example of a spin echo $T_{2}$-weighted MR image $(\mathrm{TR} / \mathrm{TE}=5000 \mathrm{~ms} / 4 \mathrm{~ms})$ of the top $(4,5,6)$ and the bottom $(1,2,3)$ NPs with concentrations $0.22 \mathrm{mg} / \mathrm{ml}(1,4) ; 0.11 \mathrm{mg} / \mathrm{ml}(2,5)$ and $0.04 \mathrm{mg} / \mathrm{ml}(3,6)$, respectively; $\mathbf{b}$ an example of a $T_{1}$-weighted MR image $(\mathrm{TR} / \mathrm{TE}=3 \mathrm{~ms} / 1.5 \mathrm{~ms})$ of the top $(4,5,6)$ and the bottom $(1,2,3)$ NPs with concentrations $0.22 \mathrm{mg} / \mathrm{ml} \quad(1,4)$; $0.11 \mathrm{mg} / \mathrm{ml}(2,5)$; and $0.04 \mathrm{mg} / \mathrm{ml}(3,6)$, respectively. 
Figure 8 Correlation between a $T_{2}$ and $\mathbf{b} T_{1}$ relaxation times and concentration of the top and the bottom $\mathrm{Fe}_{3} \mathrm{O}_{4}$ NPs.

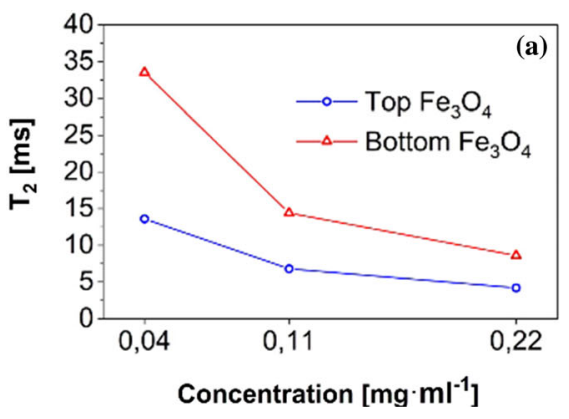

The fitting provided $r_{1}=0.0002 \mathrm{ml} / \mathrm{mg} \mathrm{s}^{-1}$ and $r_{1}=7 \times 10^{-5} \mathrm{ml} / \mathrm{mg} \mathrm{s}^{-1}$ for the bottom NP and top NPs, respectively, and $r_{2}=0.0823 \mathrm{ml} / \mathrm{mg} \mathrm{s}^{-1}$ and $r_{2}=0.0432 \mathrm{ml} / \mathrm{mg} \mathrm{s}^{-1}$ for the bottom NP and top NPs, respectively (Fig. 9). $r_{2} / r_{1}$ was found to be 411 and 617 for the bottom and top NPs, respectively.

The $r_{2} / r_{1}$ ratio provides a qualitative measure of the effectiveness of the contrast agent. The $r_{2} / r_{1}$ ratios we measured are higher than those reported so far (10 nm IONPs: $r_{2} / r_{1}=90.5$ at $9.4 \mathrm{~T}$ ) [82]. These values indicate that both the bottom and the top NPs are suitable as $T_{2}$ contrast agents. Furthermore, the top NPs are more potent than the bottom NPs.

Most publications do not provide $r_{1}$ and $r_{2}$ at $9.4 \mathrm{~T}$. A paper [83] reports $r_{2} / r_{1}$ to be in the order of 200-500 depending on the NP size $(8.8 \mathrm{~nm}-249$; $15 \mathrm{~nm}-788)$. In our case, $r_{2} / r_{1}$ was found to be 411 and 617 for the bottom and top NPs, respectively, which is in the agreement with the previous works.

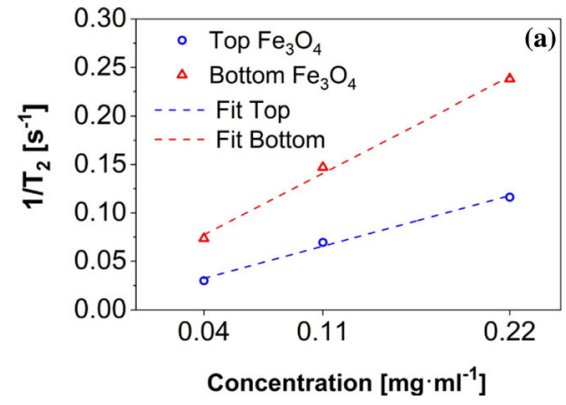

Figure 9 a Transverse $\left(1 / T_{2}\right)$ and $\mathbf{b}$ longitudinal $\left(1 / T_{1}\right)$ relaxivities obtained for top and bottom NPs at $9.4 \mathrm{~T}$. R-square (coefficient of determination) values defining the goodness are:

\section{Magnetic hyperthermia simulation and SLP analysis}

The heating rate dependences measured at various amplitudes of external magnetic field for two types of specimens are presented in Fig. 10a and b.

In Fig. 10a and b, the vertical dashed lines separate two regions of variability of the $T(\mathrm{t})$ dependences. They denote different time dependences measured at lower and higher temperatures, especially for nonlinear $T(\mathrm{t})$ dependences. The appropriate heating rates and specific loss power (SLP) values calculated for both dispersions are collected in Table 2 .

One can notice for dispersion of the top NPs that the time required to reach $45^{\circ} \mathrm{C}$ (the temperature at which the cancer cells may undergo deterioration when exposed to such conditions) was $\sim 800 \mathrm{~s}$ for the highest external magnetic field $(4 \mathrm{kA} / \mathrm{m})$. Application of alternating magnetic fields less than $3.8 \mathrm{kA} /$ $\mathrm{m}$ did not allow to reach this temperature at any reasonable period. This effect might be related to the lower particle sizes of the top NPs than those for the bottom NPs. Furthermore, the effect of coating of nanoparticles with surfactant must be considered. In

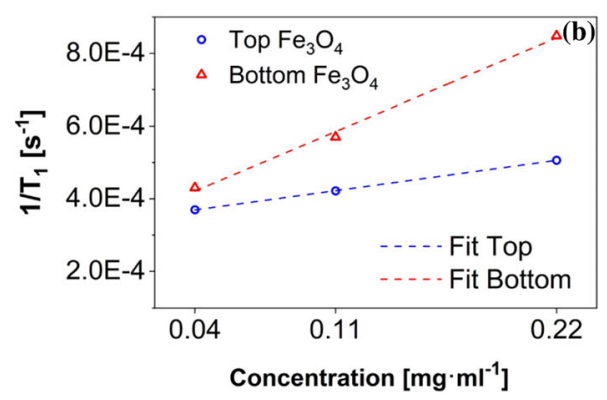

0.9647, 0.9817 for $\mathrm{r}_{1}$ for bottom and top NP, respectively, and 0.9962 and 0.9977 for $r_{2}$ of the bottom and top NP, respectively. 
Figure 10 Heating rate measured for 5 wt. $\%$ dispersions in glycerol of the top NPs (a) and the bottom NPs (b) for given amplitude of alternating external magnetic field.

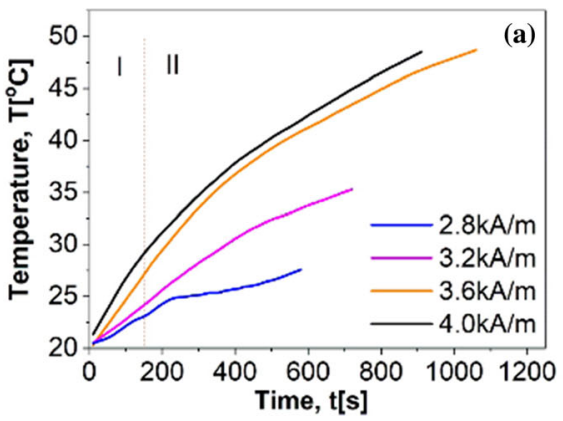

Table 2 Heating rate $\left(\frac{d T}{d t}\right)$ and specific loss power (SLP) for the top and the bottom NPs measured at various amplitudes of external magnetic field of the frequency $100 \mathrm{kHz}$

\begin{tabular}{|c|c|c|c|c|}
\hline & $\begin{array}{l}\mathrm{H}[\mathrm{kA} / \\
\mathrm{m}]\end{array}$ & & $\begin{array}{l}\frac{d T}{d t} \\
{[\mathrm{~K} /} \\
\quad \mathrm{min}]\end{array}$ & $\begin{array}{r}\text { SLP } \\
{[\mathrm{W} /} \\
\mathrm{g}]\end{array}$ \\
\hline \multirow[t]{2}{*}{ Top NPs } & 2.8 & I & 1 & 0.783 \\
\hline & & II & 0.63 & 0.49 \\
\hline \multirow[t]{5}{*}{5 wt. $\%$} & 3.2 & & 1.2 & 0.49 \\
\hline & & I & 2.6 & 2.01 \\
\hline & 3.6 & II & 1.43 & 1.10 \\
\hline & & I & 3.48 & 2.72 \\
\hline & 4.0 & II & 1.53 & 1.17 \\
\hline \multirow[t]{3}{*}{ Bottom NPs } & & I & 4.03 & 3.14 \\
\hline & 2.0 & II & 1.13 & 0.90 \\
\hline & 2.4 & & 2.91 & 2.25 \\
\hline \multirow[t]{4}{*}{5 wt. $\%$} & 2.8 & & 5.23 & 4.03 \\
\hline & 3.2 & & 7.41 & 5.67 \\
\hline & 3.6 & & 10.68 & 8.38 \\
\hline & 4.0 & & 19.84 & 15.46 \\
\hline
\end{tabular}

Fig. 10a, the $T(\mathrm{t})$ dependences are nonlinear due to the faster dissipation of the energy generated by the particles subjected to the alternating external magnetic field. In the case of the bottom NPs (Fig. 10b), reaching of $45^{\circ} \mathrm{C}$ when exposed to the alternating magnetic field of $4 \mathrm{kA} / \mathrm{m}$ takes less than $100 \mathrm{~s}$. Only a little longer $(\sim 200 \mathrm{~s})$ takes heating of this specimen to $45^{\circ} \mathrm{C}$ under the alternating magnetic field of $2.8 \mathrm{kA} / \mathrm{m}$. Furthermore, in this range of external magnetic fields the $T(\mathrm{t})$ dependences are more linear. Nonlinear time-temperature dependences were measured only for the lowest external magnetic field (of $2 \mathrm{kA} / \mathrm{m}$ ). As the specific loss power is related to the $\mathrm{dT} / \mathrm{dt}$ dependences, similar tendencies were noticed for the SLP values. In the case, the bottom NPs much higher SLP values (of one order of magnitude) than those for the top NPs were measured.

\section{Cytotoxic effect of NPs}

The viability test presented in Fig. 11 showed that cytotoxic effect of the smallest concentration of both the top and the bottom NPs was not observed for SW480 and SW620 cell lines after $3 \mathrm{~h}$ and $24 \mathrm{~h}$ of incubation time. Moreover, addition of $50 \mu \mathrm{g} / \mathrm{ml}$ of the top NPs and the bottom NPs to the cell culture did not change the percentage of cell viability after 3-h incubation. However, an increase of the incubation time to $24 \mathrm{~h}$ caused significant decrease of the SW480 and SW620 cells viability. Furthermore, the highest decrease of number of live cells was observed for the cells, cultured with $100 \mu \mathrm{g} / \mathrm{ml}$ of the top NPs and the bottom NPs. This concentration of the top NPs caused decrease of SW480 cells viability by around $20 \%$ and $24 \%$, respectively, after $3 \mathrm{~h}$ and $24 \mathrm{~h}$ of incubation, while for the bottom NPs the viability of cells was higher by about 4\%. For SW620 cell line, the viability of cells, cultured with $100 \mu \mathrm{g} / \mathrm{ml}$ of the top NPs, was $90 \%$ and $82 \%$ for $3 \mathrm{~h}$ and $24 \mathrm{~h}$ of incubation, while, respectively, for the bottom NPs$83 \%$ and $78 \%$. The low cytotoxicity of the top NPs and the bottom NPs can be attributed to the coating of the iron-oxide NPs by triethanolammonium oleate. This substance, as well as triethanolamine by itself, is biocompatible and is very often used in cosmetics and medicines and even has been used as an indirect food additive [45, 84]. However, the MTS assay showed that the bottom NPs caused higher decrease of cells viability than the top NPs, which depends on the nanoparticle sizes. Smaller NPs are more toxic than bigger ones, because they have higher active surface [85, 86]. Furthermore, these studies have shown an impact of NPs concentration on the viability of cells. Higher concentration of NPs caused higher percentage of cells' deaths. In such case, the interactions between cells and NPs increase and processes leading to cell death are more active [85]. 
Figure 11 Viability of colon cancer cells: SW480 (a); SW620 (b); cultured with $5 \mu \mathrm{g} / \mathrm{ml}$ (I), $50 \mu \mathrm{g} / \mathrm{ml}$ (II) and $100 \mu \mathrm{g} / \mathrm{ml}$ (III) top NPs and bottom NPs during $3 \mathrm{~h}$ (blue color) and $24 \mathrm{~h}$ (red color). Data were considered as significant when $* p<0.05$ vs. Control (X).
SW480

(a)

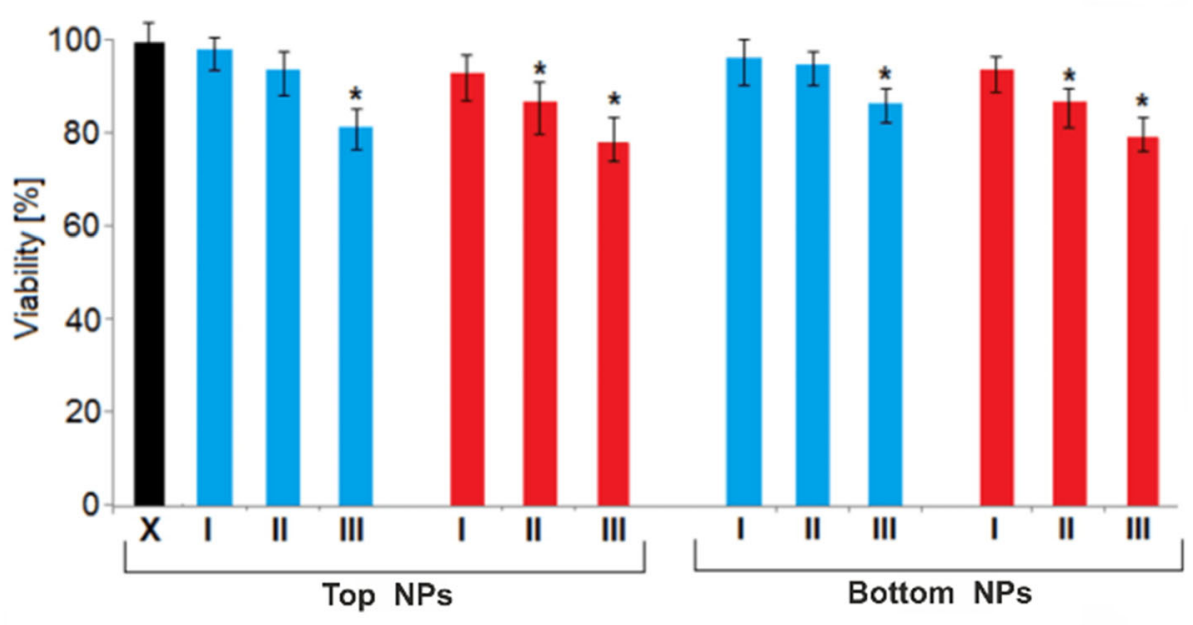

SW620

(b)

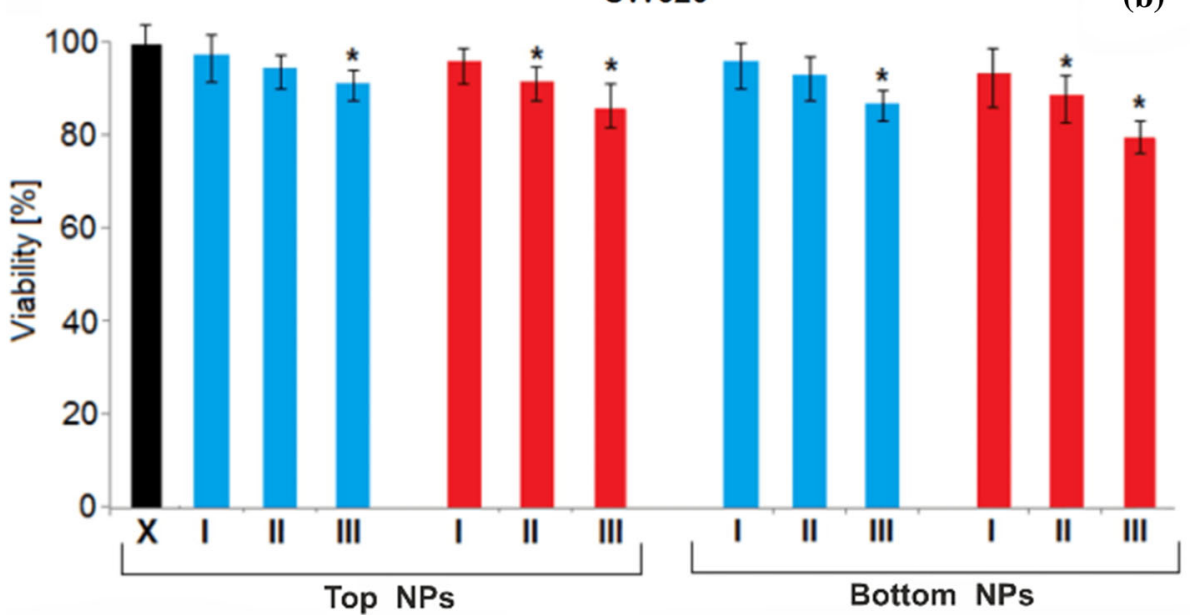

Moreover, longer incubation time for cells exposed to the presence of NPs and thus larger number of NPs getting into the contact with the cells intensified the impairing of the functions of major components of cell, namely mitochondria, nucleus and DNA [87].

\section{Fibroblast cell studies}

Viability and apoptosis on human dermal fibroblasts tests were performed to support the result of cytotoxicity depicted by MTT assay and to confirm the lack of cytotoxicity on cells routinely transplanted in chronic wounds treatment. Morphology microscopic assessment, proliferation and ROS studies were performed due to dysfunctions observed in senescencelike phenotype fibroblasts present in chronic wounds. All studied samples remained sterile during whole experiment, but macroscopic and microscopic conglomerates were present in some of the NPs samples (Fig. 12).

Highest viability was obtained in samples with $8 \mu \mathrm{l}$ and $16 \mu \mathrm{l}$ per well of studied NPs (Table 3). Addition of NPs increased the viability of the cells in comparison with the control samples.

Fibroblasts are one of the key cells in chronic wound healing due to the production of extracellular matrix that is required to fill the wound with a newly synthesized tissue [88] and maintaining high viability of cells in wound edge.

Nanoparticles did not cause an increase of percentage of apoptotic cells in the culture (Table 4). Interestingly, the lowest concentration of particles was correlated with the highest percentage of apoptotic cells, which suggest that a higher concentration is safer. 


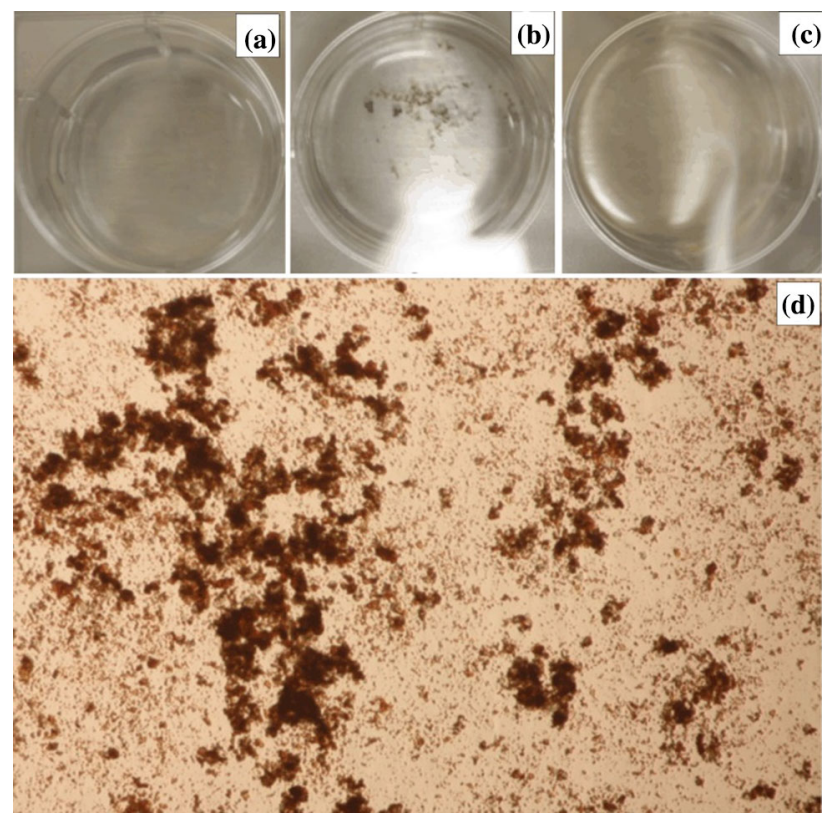

Figure 12 The 3-well dish with sample: $\mathbf{a}$ control, $\mathbf{b}$ bottom NPs, c top NPs; $\mathbf{d}$ microscopic image of fibroblast cell culture with $16 \mu \mathrm{l}$ per well of bottom NPs.

Table 3 Viability of fibroblasts depending on samples concentration and type of particles

\begin{tabular}{llllll}
\hline Sample name & $2 \mu 1$ & $8 \mu 1$ & $16 \mu l$ & $32 \mu l$ & Mean \\
\hline Control & 76 & 72 & 76 & 61.5 & 71.4 \\
Bottom NPs & 89.5 & 92.5 & 96 & 98 & 94.0 \\
Top NPs & 56.5 & 57.5 & 81 & 83 & 69.5 \\
\hline
\end{tabular}

Table 4 Percentage of apoptotic fibroblasts depending on samples concentration and type of particles

\begin{tabular}{llllll}
\hline Sample name & $2 \mu \mathrm{l}$ & $8 \mu \mathrm{l}$ & $16 \mu \mathrm{l}$ & $32 \mu \mathrm{l}$ & Mean \\
\hline Control & 6 & 1 & 4 & 0 & 2.8 \\
Bottom NPs & 6 & 2.5 & 0.5 & 0.5 & 2.4 \\
Top NPs & 1.5 & 4.5 & 1 & 3 & 2.5 \\
\hline
\end{tabular}

Table 5 Impact of particles on oxidative stress in cells

\begin{tabular}{llllll}
\hline Sample name & $2 \mu \mathrm{l}$ & $8 \mu \mathrm{l}$ & $16 \mu \mathrm{l}$ & $32 \mu \mathrm{l}$ & Mean \\
\hline Control & 5 & 4 & 9 & 10 & 8 \\
Bottom NPs & 7 & 9 & 4 & 8 & 7 \\
Top NPs & 6 & 3 & 11 & 8 & 7 \\
\hline
\end{tabular}

Table 6 Population doubling of fibroblasts depending on samples' concentration and type of particles

\begin{tabular}{lccccc}
\hline Sample name & $2 \mu \mathrm{l}$ & $8 \mu \mathrm{l}$ & $16 \mu \mathrm{l}$ & $32 \mu \mathrm{l}$ & Mean \\
\hline Control & 0.4 & 1.9 & 1.2 & 0.4 & 1.0 \\
Bottom NPs & 3.9 & 6.7 & 4.2 & 6.5 & 5.3 \\
Top NPs & 2.6 & 3.5 & 2.8 & 3.4 & 3.1 \\
\hline
\end{tabular}

Also, oxidative stress in cells incubated with nanoparticles was not greater than in control sample (Table 5). Levels of oxidative stress and percentage of apoptotic cells suggest that particles are potentially safe in clinical use. If they revealed cytotoxic effect, it may hamper the healing process in wound (Table 6).

Population doubling was highest in cultures where $8 \mu \mathrm{l}$ of NPs was added (Table 5). Bottom NPs had the greatest ability to stimulate the proliferation of cells. Distinct increase in cellular proliferative activity may lead to the rapid and almost complete closure of chronic wound [87].

Wound healing is the highly coordinated process [89] in which fibroblasts play a key role [88], and any disruption may prolong each stage of healing [89]. $\mathrm{Fe}_{3} \mathrm{O}_{4}$ nanoparticles have found a lot of applications in various fields, and usage of this particles gives hope for definite wound closure. Our studies shown that fibroblast culture remained sterile, highly viable and no cytotoxic effect was observed, which confirms their potential in chronic wounds healing.

\section{Conclusions}

In the present work, we have discussed a novel technique of producing the $\mathrm{Fe}_{3} \mathrm{O}_{4}$ NPs. The nanoparticles were synthesized by the co-precipitation method and stabilized by the triethanolammonium oleate. The fabrication protocol allowed to produce two types of magnetite NPs in one step. The top and bottom NPs differed in their average diameters (11 $\mathrm{nm}$ and $19 \mathrm{~nm}$, respectively) and size distributions. It is reflected in their physical properties, and application potential in theranostics. Both types of the stabilized NPs are hydrophilic and form the uniform dispersions in water, which are stable and do not sediment for months. VSM magnetometry has shown the superparamagnetic behavior of both types of NPs at room temperature, while Mössbauer spectroscopy revealed pronounced ferrimagnetic 
interaction, especially for larger NPs. The XRD as well as Mössbauer spectra analysis suggests the formation of maghemite layers on top of the magnetite core of NPs. This can be attributed to the oxidation of magnetite that occurs when the NPs are washed and dispersed in the water after their precipitation. Both NPs indicated promising results regarding their use as heating agents in hyperthermia and contrast agents in MRI. In addition, stabilized NPs have revealed low cytotoxicity. All observed properties of the both types of NPs indicate their potential in MRIguided hyperthermia cancer treatment. Fibroblast dysfunction is one of key factors in the chronic wounds; therefore, positive impact on their viability and proliferation suggests possible applications of NPs in non-healing wounds treatment.

\section{Acknowledgements}

The authors acknowledge the financial support from the Belarusian Republic Foundation for Basic Research (project no. X20MS-014) and National Science Centre (Poland) (project "Harmonia" no. 2018/30/M/NZ5/00844).

\section{Declaration}

Conflict of interest The authors declare that they have no conflict of interest.

Open Access This article is licensed under a Creative Commons Attribution 4.0 International License, which permits use, sharing, adaptation, distribution and reproduction in any medium or format, as long as you give appropriate credit to the original author(s) and the source, provide a link to the Creative Commons licence, and indicate if changes were made. The images or other third party material in this article are included in the article's Creative Commons licence, unless indicated otherwise in a credit line to the material. If material is not included in the article's Creative Commons licence and your intended use is not permitted by statutory regulation or exceeds the permitted use, you will need to obtain permission directly from the copyright holder. To view a copy of this licence, visit http://creativecommons.org/licen ses/by $/ 4.0 /$.

\section{References}

[1] Vorobyova SA, Rzheussky SE (2018) Nanomedicine nanoprticles of metals and their inorganic compounds obtained through interphase and redox-transmetalation interaction: application in medicine and pharmacology. Bull RSMU 6:102-106. https://doi.org/10.24075/brsmu.2018.076

[2] Ling D, Hyeon T (2013) Chemical design of biocompatible iron oxide nanoparticles for medical applications. Small 9:1450-1466. https://doi.org/10.1002/smll.201202111

[3] Anderson SD, Gwenin VV, Gwenin CD (2019) Magnetic functionalized nanoparticles for biomedical, drug delivery and imaging applications. Nanoscale Res Lett 14:188. http s://doi.org/10.1186/s11671-019-3019-6

[4] Popescu RC, Andronescu E, Vasile BS (2019) Recent advances in magnetite nanoparticle functionalization for nanomedicine. Nanomaterials 9:1791. https://doi.org/10.339 0/nano9121791

[5] Roca AG, Gutiérrez L, Gavilán $\mathrm{H}$ et al (2018) Design strategies for shape-controlled magnetic iron oxide nanoparticles. Adv Drug Deliv Rev 138:68-104. https://doi. org/10.1016/j.addr.2018.12.008

[6] Douglas FJ, MacLaren DA, Maclean N et al (2016) Gadolinium-doped magnetite nanoparticles from a singlesource precursor. RSC Adv 6:74500-74505. https://doi.org/ $10.1039 / \mathrm{c} 6 \mathrm{ra} 18095 \mathrm{~g}$

[7] Lak A, Niculaes D, Anyfantis GC et al (2016) Facile transformation of $\mathrm{FeO} / \mathrm{Fe} 3 \mathrm{O} 4$ core-shell nanocubes to Fe3O4 via magnetic stimulation. Nat Publ Gr 6:33295. h ttps://doi.org/10.1038/srep33295

[8] Nandwana V, Zhou R, Mohapatra J et al (2018) Exchange coupling in soft magnetic nanostructures and its direct effect on their theranostic properties. ACS Appl Mater Interfaces 10:27233-27243. https://doi.org/10.1021/acsami.8b09346

[9] Hervault A, Thanh NTK (2014) Magnetic nanoparticlebased therapeutic agents for thermo-chemotherapy treatment of cancer. Nanoscale 6:11553-11573. https://doi.org/10.103 9/c4nr03482a

[10] Dutz S, Hergt R (2014) Magnetic particle hyperthermia - a promising tumour therapy? Nanotechnology 25:452001. h ttps://doi.org/10.1088/0957-4484/25/45/452001

[11] Abdulla-Al-Mamun M, Kusumoto Y, Zannat T et al (2013) Au-ultrathin functionalized core-shell (Fe3O4@Au) monodispersed nanocubes for a combination of magnetic/plasmonic photothermal cancer cell killing. RSC Adv 3:7816-7827. https://doi.org/10.1039/c3ra21479f

[12] Deissler RJ, Martens MA, Wu Y, Brown R (2013) Brownian and Néel relaxation times in magnetic particle dynamics. In: 2013 International Workshop on Magnetic Particle Imaging (IWMPI). IEEE, Berkeley, pp 1-1 
[13] Bowers S, Franco E (2020) Chronic wounds: evaluation and management. Am Fam Physician 101:159-166

[14] Frykberg RG, Banks J (2015) Challenges in the treatment of chronic wounds. Adv Wound Care 4:560-582. https://doi. org/10.1089/wound.2015.0635

[15] Chen S, Liu B, Carlson MA et al (2017) Recent advances in electrospun nanofibers for wound healing. Nanomedicine 12:1335-1352. https://doi.org/10.2217/nnm-2017-0017

[16] Ghaseminezhad SM, Shojaosadati SA, Meyer RL (2018) $\mathrm{Ag} / \mathrm{Fe} 3 \mathrm{O} 4$ nanocomposites penetrate and eradicate $\mathrm{S}$. aureus biofilm in an in vitro chronic wound model. Colloids Surfaces B Biointerfaces 163:192-200. https://doi.org/10.1016/ j.colsurfb.2017.12.035

[17] Yang Y, Ren S, Zhang X et al (2018) Safety and efficacy of PLGA(Ag-Fe3O4)-Coated dental implants in inhibiting bacteria adherence and osteogenic inducement under a magnetic field. Int J Nanomed 13:3751-3762. https://doi. org/10.2147/IJN.S159860

[18] Khansa I, Schoenbrunner AR, Kraft CT, Janis JE (2019) Silver in wound care-friend or foe?: a comprehensive review. Plast Reconstr Surg Glob Open 7:1-10. https://doi.org/10. 1097/GOX.0000000000002390

[19] Woodley DT (2017) Distinct fibroblasts in the papillary and reticular dermis: Implications for wound healing. Dermatol Clin 35:95-100. https://doi.org/10.1016/j.det.2016.07.004

[20] Desjardins-Park HE, Foster DS, Longaker MT (2018) Fibroblasts and wound healing: an update. Regen Med 13:491-495. https://doi.org/10.2217/rme-2018-0073

[21] Han X, Zhang WH, Wang WQ et al (2020) Cancer-associated fibroblasts in therapeutic resistance of pancreatic cancer: Present situation, predicaments, and perspectives. Biochim Biophys Acta Rev Cancer 1874:188444. https://doi.org/10. 1016/j.bbcan.2020.188444

[22] Mihai MM, Dima MB, Dima B, Holban AM (2019) Nanomaterials for wound healing and infection control. Materials (Basel) 12:1-16. https://doi.org/10.3390/ma12132176

[23] Majeed MI, Guo J, Yan W, Tan B (2016) Preparation of magnetic iron oxide nanoparticles (MIONs) with improved saturation magnetization using multifunctional polymer ligand. Polymers (Basel) 8:1-16. https://doi.org/10.3390/ polym8110392

[24] Barrow M, Taylor A, Murray P et al (2015) Design considerations for the synthesis of polymer coated iron oxide nanoparticles for stem cell labelling and tracking using MRI. Chem Soc Rev 44:6733-6748. https://doi.org/10.1039/c5c s00331h

[25] Fernández-Barahona I, Muñoz-Hernando M, Herranz F (2019) Microwave-driven synthesis of iron-oxide nanoparticles for molecular imaging. Molecules 24. https://doi.org/ 10.3390/molecules24071224
[26] Zhu XH, Hang QM (2013) Microscopical and physical characterization of microwave and microwave-hydrothermal synthesis products. Micron 44:21-44. https://doi.org/10.101 6/j.micron.2012.06.005

[27] Lalatonne Y, Richardi J, Pileni MP (2004) Van der Waals versus dipolar forces controlling mesoscopic organizations of magnetic nanocrystals. Nat Mater 3:121-125. https://doi. org/10.1038/nmat1054

[28] Maggioni D, Arosio P, Orsini F et al (2014) Superparamagnetic iron oxide nanoparticles stabilized by a poly(amidoamine)-rhenium complex as potential theranostic probe. Dalt Trans 43:1172-1183. https://doi.org/10.1039/c3d t52377b

[29] Costa C, Brandão F, Bessa MJ et al (2016) In vitro cytotoxicity of superparamagnetic iron oxide nanoparticles on neuronal and glial cells. Evaluation of nanoparticle interference with viability tests. J Appl Toxicol 36:361-372. h ttps://doi.org/10.1002/jat.3213

[30] Ma W, Gehret PM, Hoff RE et al (2019) The investigation into the toxic potential of iron oxide nanoparticles utilizing rat pheochromocytoma and human neural stem cells. Nanomaterials 9. https://doi.org/10.3390/nano9030453

[31] Fernández-Bertólez N, Costa C, Brandão F et al (2018) Neurotoxicity assessment of oleic acid-coatediron oxide nanoparticles in SH-SY5Y cells. Toxicology 406407:8191. h ttps://doi.org/10.1016/j.tox.2018.06.003

[32] Gonzales M, Mitsumori LM, Kushleika JV et al (2010) Cytotoxicity of iron oxide nanoparticles made from the thermal decomposition of organometallics and aqueous phase transfer with Pluronic F127. Contrast Media Mol Imaging 5:286-293. https://doi.org/10.1002/cmmi.391

[33] Ding HL, Zhang YX, Wang S et al (2012) Fe3O4@SiO2 core/shell nanoparticles: the silica coating regulations with a single core for different core sizes and shell thicknesses. Chem Mater 24:4572-4580. https://doi.org/10.1021/c m302828d

[34] Dolci S, Ierardi V, Remskar M et al (2013) Chemicalphysical properties, morphology, and magnetic investigations on new cystine functionalized ultra-small super-paramagnetic iron-oxide nanoparticles. J Mater Sci 48:1283-1291. https://doi.org/10.1007/s10853-012-6871-7

[35] Hou X, Wang X, Liu R et al (2017) Facile synthesis of multifunctional Fe3O4@SiO2@Au magneto-plasmonic nanoparticles for MR/CT dual imaging and photothermal therapy. RSC Adv 7:18844-18850. https://doi.org/10.1039/c 7ra00925a

[36] Maximenko A, Depciuch J, Łopuszyńska N et al (2020) Fe3O4@SiO2@Au nanoparticles for MRI-guided chemo/ NIR photothermal therapy of cancer cells. RSC Adv 10:26508-26520. https://doi.org/10.1039/D0RA03699D 
[37] Dolci S, Domenici V, Vidili G et al (2016) Immune compatible cystine-functionalized superparamagnetic iron oxide nanoparticles as vascular contrast agents in ultrasonography. RSC Adv 6:2712-2723. https://doi.org/10.1039/c5ra19652c

[38] Dolci S, Ierardi V, Gradisek A et al (2013) Precursors of magnetic resonance imaging contrast agents based on Cystine-coated iron-oxide nanoparticles. Curr Phys Chem 3:493-500. https://doi.org/10.2174/18779468113036660009

[39] Hergt R, Dutz S, Röder M (2008) Effects of size distribution on hysteresis losses of magnetic nanoparticles for hyperthermia. J Phys Condens Matter 20:385214. https://doi.org/ $10.1088 / 0953-8984 / 20 / 38 / 385214$

[40] Sodipo BK, Aziz AA (2016) Recent advances in synthesis and surface modification of superparamagnetic iron oxide nanoparticles with silica. J Magn Magn Mater 416:275-291. https://doi.org/10.1016/j.jmmm.2016.05.019

[41] Mandel K, Szczerba W, Thunemann AF et al (2012) Nitric acid-stabilized superparamagnetic iron oxide nanoparticles studied. J Nanoparticle Res 14:1066. https://doi.org/10.1007/ s11051-012-1066-3

[42] Mehrmohammadi M, Yoon KY, Qu M et al (2011) Enhanced pulsed magneto-motive ultrasound imaging using superparamagnetic nanoclusters. Nanotechnology 22:045502. htt ps://doi.org/10.1088/0957-4484/22/4/045502

[43] Wegmann M, Scharr M (2018) Synthesis of magnetic iron oxide nanoparticles. In: Kohl M (ed) Deigner H-P. Tools and Quantitative Approaches. Elsevier Inc., Precision Medicine, pp 145-181

[44] Hartwig A, Commission MAK (2017) Triethanolamine/2[bis(2-hydroxy- ethyl)amino]ethanol. MAK-Collection Occup Heal Saf 2:1568-1609. https://doi.org/10.1002/3527 600418.mb10271kske4817

[45] Fiume MM, Heldreth B, Bergfeld WF et al (2013) Safety assessment of triethanolamine and triethanolamine-containing ingredients as used in cosmetics. Int J Toxicol 32:59S83S. https://doi.org/10.1177/1091581813488804

[46] Xia T, Wang J, Wu C et al (2012) Novel complex-coprecipitation route to form high quality triethanolamine-coated Fe3O4 nanocrystals: their high saturation magnetizations and excellent water treatment properties. CrystEngComm 14:5741-5744. https://doi.org/10.1039/c2ce25813g

[47] Han C, Zhu D, Wu H et al (2016) TEA controllable preparation of magnetite nanoparticles (Fe3O4NPs) with excellent magnetic properties. J Magn Magn Mater 408:213-216. h ttps://doi.org/10.1016/j.jmmm.2016.02.060

[48] Maity D, Chandrasekharan P, Pradhan P et al (2011) Novel synthesis of superparamagnetic magnetite nanoclusters for biomedical applications. J Mater Chem 21:14717-14724. h ttps://doi.org/10.1039/c1jm11982f
[49] Kholmetskii AL, Vorobyova SA, Lesnikovich AI et al (2005) A novel route for the preparation of magnetic fluids. Mater Lett 59:1993-1996. https://doi.org/10.1016/j.matlet.2 004.06.078

[50] Davies KJ, Wells S, Charles SW (1993) The effect of temperature and oleate adsorption on the growth of maghemite particles. J Magn Magn Mater 122:24-28. https://doi.org/10. 1016/0304-8853(93)91031-2

[51] Massart R (1981) Preparation of aqueous magnetic liquids in alkaline and acidic media. IEEE Trans Magn 17:1247-1248. https://doi.org/10.1109/TMAG.1981.1061188

[52] Rodríguez-Carvajal J (1990) Introduction to the program FULLPROF: refinement of crystal and magnetic structures from powder and single crystal data. Tech Report, CEACNRS, Saclay, Fr

[53] Thompson P, Cox DE, Hastings JB (1987) Rietveld refinement of Debye-Scherrer synchrotron X-ray data from A1203. J Appl Crystallogr 20:79-83. https://doi.org/10.1107/ S0021889887087090

[54] Smolkova IS, Kazantseva NE, Babayan V et al (2015) Alternating magnetic field energy absorption in the dispersion of iron oxide nanoparticles in a viscous medium. J Magn Magn Mater 374:508-515. https://doi.org/10.1016/j. jmmm.2014.08.096

[55] Kitala D, Kawecki M, Klama-Baryła A et al (2017) The isolation and production of the ready-to-use product (the Amniotic Stem Cell Culture) in accordance with good manufacturing practice regulations. Stem Cells Dev 26:694-707. https://doi.org/10.1089/scd.2016.0198

[56] Kitala D, Kawecki M, Klama-Baryła A et al (2016) Allogeneic vs. autologous skin grafts in the therapy of patients with burn injuries: a restrospective, open-label clinical study with pair matching. Adv Clin Exp Med 25:923-929. http s://doi.org/10.17219/acem/61961

[57] Laconte L, Nitin N, Bao G (2005) Magnetic nanoparticle probes. Mater Today 8:32-38. https://doi.org/10.1016/S136 9-7021(05)00893-X

[58] Swanson HE, McMurdie HF, Morris MC, Evans EH (1967) Standard X-ray diffraction powder patterns. United States Department of Commerce, Washington

[59] Pecharromán C, Gonzalez-Carreno T, Iglesias JE (1995) The infrared dielectric properties of maghemite, $\gamma$-Fe2O3, from reflectance measurement on pressed powders. Phys Chem Miner 22:21-29

[60] Qiao L, Fu Z, Li J et al (2017) Standardizing size- and shapecontrolled synthesis of monodisperse magnetite (Fe3O4) nanocrystals by identifying and exploiting effects of organic impurities. ACS Nano 11:6370-6381. https://doi.org/10.10 21/acsnano. $7 b 02752$ 
[61] Richard J, Lewis S (2007) Hawley's condensed chemical dictionary, 15th edn. Wiley, New Jersey

[62] Qin W, Yang C, Yi R, Gao G (2010) Hydrothermal synthesis and characterization of single-crystalline $\alpha$-Fe 2 O 3 Nanocubes. J Nanomater 2011:5 pages. https://doi.org/10.1155/ 2011/159259

[63] Wojciechowski G, Brzezinski B (2002) Formation of hydrogen-bonded chains through inter- and intra-molecular hydrogen bonds by 5,5'-dinitro-2,2'-biphenol with a strong base of guanidine-like character and triethylamine. J Mol Struct 607:149-154. https://doi.org/10.1016/S0022-2860(01 00904-8

[64] Wojciechowski G, Brzezinski B (2002) Formation of hydrogen-bonded complexes of $3,3^{\prime}, 5,5^{\prime}$-tetrabromo-2,2'biphenol with MTBD and triethylamine. J Mol Struct 616:67-71

[65] Wang J, Sun J, Sun Q, Chen Q (2003) One-step hydrothermal process to prepare highly crystalline $\mathrm{Fe} 3 \mathrm{O} 4$ nanoparticles with improved magnetic properties. Mater Res Bull 38:1113-1118. https://doi.org/10.1016/S0025-5408(03)0012 $9-6$

[66] Lemine OM, Omri K, Zhang B et al (2012) Sol-gel synthesis of $8 \mathrm{~nm}$ magnetite (Fe3O4) nanoparticles and their magnetic properties. Superlattices Microstruct 52:793-799. https://doi. org/10.1016/j.spmi.2012.07.009

[67] Mahdavi M, Bin AM, Haron MJ et al (2013) Synthesis, surface modification and characterisation of biocompatible magnetic iron oxide nanoparticles for biomedical applications. Molecules 18:7533-7548. https://doi.org/10.3390/mo lecules 18077533

[68] Frison R, Cernuto G, Cervellino A et al (2013) Magnetitemaghemite nanoparticles in the $5-15 \mathrm{~nm}$ range: Correlating the core-shell composition and the surface structure to the magnetic properties. A total scattering study. Chem Mater 25:4820-4827. https://doi.org/10.1021/cm403360f

[69] Patil RM, Shete PB, Thorat ND et al (2014) Non-aqueous to aqueous phase transfer of oleic acid coated iron oxide nanoparticles for hyperthermia application. RSC Adv 4:4515-4522. https://doi.org/10.1039/c3ra44644a

[70] Haracz S, Hilgendorff M, Rybka JD, Giersig M (2015) Effect of surfactant for magnetic properties of iron oxide nanoparticles. Nucl Instruments Methods Phys Res Sect B 364:120-126. https://doi.org/10.1016/j.nimb.2015.08.035

[71] Bin NH, Song IC, Hyeon T (2009) Inorganic nanoparticles for MRI contrast agents. Adv Mater 21:2133-2148. https://d oi.org/10.1002/adma.200802366

[72] Hiergeist R, Andrä W, Buske N et al (1999) Application of magnetite ferrofluids for hyperthermia. J Magn Magn Mater 201:420-422. https://doi.org/10.1016/S0304-8853(99)0014 $5-6$
[73] Jensen PJ, Pastor GM (2003) Low-energy properties of twodimensional magnetic nanostructures: Interparticle interactions and disorder effects. New J Phys 5. https://doi.org/10. 1088/1367-2630/5/1/368

[74] De JC, Sangregorio C, Mattei G et al (2001) Nanostructure and magnetic properties of CoNi-alloy-based nanoparticles dispersed in a silica matrix. J Magnet Magn Mater 230:1912-1914. https://doi.org/10.1016/S0304-8853(00)00 660-0

[75] Plouffe BD, Nagesha DK, Dipietro RS et al (2011) Thermomagnetic determination of $\mathrm{Fe} 3 \mathrm{O} 4$ magnetic nanoparticle diameters for biomedical applications. J Magn Magn Mater 323:2310-2317. https://doi.org/10.1016/j.jmmm.2011.04. 013

[76] Stauch C, Späth S, Ballweg T et al (2017) Nanostructured micro-raspberries from superparamagnetic iron oxide nanoparticles: studying agglomeration degree and redispersibility of nanoparticulate powders via magnetisation measurements. J Colloid Interface Sci 505:605-614. https://d oi.org/10.1016/j.jcis.2017.06.047

[77] Kuchma E, Kubrin S, Soldatov A (2018) The local atomic structure of colloidal superparamagnetic iron oxide nanoparticles for theranostics in oncology. Biomedicines 6:78. https://doi.org/10.3390/biomedicines6030078

[78] Joos A, Rümenapp C, Wagner FE, Gleich B (2016) Characterisation of iron oxide nanoparticles by Mössbauer spectroscopy at ambient temperature. J Magn Magn Mater 399:123-129. https://doi.org/10.1016/j.jmmm.2015.09.060

[79] Chlan V, Zukrowski J, Bosak A et al (2018) Effect of low Zn doping on the Verwey transition in magnetite single crystals: Mössbauer spectroscopy and X-ray diffraction. Phys Rev B 98:125138. https://doi.org/10.1103/PhysRevB.98.125138

[80] Singamaneni S, Bliznyuk VN, Binek C, Tsymbal EY (2011) Magnetic nanoparticles: recent advances in synthesis, selfassembly and applications. J Mater Chem 21:16819-16845. https://doi.org/10.1039/c1jm11845e

[81] Vaishnava PP, Senaratne U, Buc EC et al (2007) Magnetic properties of $\gamma-\mathrm{Fe} 2 \mathrm{O} 3$ nanoparticles incorporated in a polystyrene resin matrix. Phys Rev B 76:024413. https://doi. org/10.1103/PhysRevB.76.024413

[82] Clements TW, Sarsons C, Platnich CM et al (2016) Maltolfunctionalized $\mathrm{Fe} 3 \mathrm{O} 4$ nanoparticles as $\mathrm{T} 2$ magnetic resonance imaging contrast agents. ChemistrySelect 1:1602-1606. https://doi.org/10.1039/d1 ra02695j

[83] Dash A, Blasiak B, Tomanek B et al (2021) Supporting information colloidally stable monodisperse Fe nanoparticles as $\mathrm{T} 2$ contrast agents for high field clinical and pre-clinical magnetic resonance imaging. ACS Appl Nano Mater 4:1235-1242. https://doi.org/10.1021/acsanm.0c02848 
[84] Nguyen AK, Gittard SD, Koroleva A et al (2013) Twophoton polymerization of polyethylene glycol diacrylate scaffolds with riboflavin and triethanolamine used as a water-soluble photoinitiator. Regen Med 8:725-738. http s://doi.org/10.2217/rme.13.60

[85] Xie Y, Liu D, Cai C et al (2016) Size-dependent cytotoxicity of $\mathrm{Fe} 3 \mathrm{O} 4$ nanoparticles induced by biphasic regulation of oxidative stress in different human hepatoma cells. Int $\mathrm{J}$ Nanomed 11:3557-3570. https://doi.org/10.2147/IJN. S105575

[86] Qu C, Qian S, Chen L et al (2019) Size-dependent bacterial toxicity of hematite particles. Environ Sci Technol 53:8147-8156. https://doi.org/10.1021/acs.est.9b00856

[87] Brunner TJ, Wick P, Manser P et al (2006) In vitro cytotoxicity of oxide nanoparticles: comparison to asbestos, silica, and the effect of particle solubility. Environ Sci Technol 40:4374-4381. https://doi.org/10.1021/es052069i

[88] Wiegand C, Abel M, Hipler UC, Elsner P (2019) Effect of non-adhering dressings on promotion of fibroblast proliferation and wound healing in vitro. Sci Rep 9:4320. https://doi. org/10.1038/s41598-019-40921-y

[89] Naskar A, Kim KS (2020) Recent advances in nanomaterialbased wound-healing therapeutics. Pharmaceutics 12:499. h ttps://doi.org/10.3390/pharmaceutics12060499

Publisher's Note Springer Nature remains neutral with regard to jurisdictional claims in published maps and institutional affiliations. 